\title{
28 Research Suare \\ Historical Variability And Future Changes In Seasonal Extreme Temperature Over Iran
}

\section{Azar Zarrin ( $\nabla$ zarrin@um.ac.ir)}

Ferdowsi University of Mashhad https://orcid.org/0000-0002-4542-3176

Abbasali Dadashi-Roudbari

Ferdowsi University of Mashhad

\section{Samira Hassani}

Ferdowsi University of Mashhad

\section{Research Article}

Keywords: Extreme Temperature Indices (ETI), CMIP5 Bias-Correction, Independence Weighted Mean (IWM), Multi-Model Ensembles (MME), Iran

Posted Date: August 10th, 2021

DOI: https://doi.org/10.21203/rs.3.rs-739242/v1

License: (c) (1) This work is licensed under a Creative Commons Attribution 4.0 International License. Read Full License 


\section{Abstract}

The extreme temperature indices (ETI) are an important indicator of climate change, the detection of their changes over the next years can play an important role in the Climate Action Plan (CAP). In this study, four temperature indices (Mean of daily minimum temperature (TN), Mean of daily maximum temperature (TX), Cold-spell duration index (CSDI), and Warm-spell duration index (WSDI)) were defined by ETCCDI and two new indices of the Maximum number of consecutive frost days (CFD) and the Maximum number of consecutive summer days (CSU) were calculated to examine ETIs in Iran under climate change conditions. We used minimum and maximum daily temperature of five General circulation models (GCMs) including HadGEM2-ES, IPSL-CM5A-LR, GFDL-ESM2M, MIROC-ESM-CHEM, and NorESM1-M from the set of CMIP5 Bias-Correction models. We investigated Two Representative Concentration Pathway (RCP) scenarios of RCP4.5 and RCP8.5 - during the historical (1965-2005) and future (2021-2060 and 2061-2100) periods. The performance of each model was evaluated using the Taylor diagram on a seasonal scale. Among models, GFDL-ESM2M and HadGEM2-ES models showed the highest, and NorESM1-M and IPSL-CM5A-LR models showed the lowest performance in Iran. Then an ensemble model was generated using Independence Weighted Mean (IWM) method. The results of multimodel ensembles (MME) showed a higher performance compared to individual CMIP5 models in all seasons. Also, the uncertainty value was significantly reduced, and the correlation value of the MME model reached 0.95 in all seasons. Additionally, it is found that WSDI and CSU indices showed positive anomalies in future periods and CSDI and CFD showed negative anomalies throughout Iran. Also, at the end of the $21^{\text {st }}$ century, no cold spells are projected in almost every part of Iran. The CSU index showed that Iran's summer days are increasing sharply, according to the results of the RCP8.5 scenario in spring (MAM) and autumn (SON), the CSU will increase by 18.79 and 20.51 days, respectively at the end of the $21^{\text {st }}$ century. It is projected that in the future, the spring and autumn seasons will be shorter and, summers, will be much longer than before.

\section{Introduction}

Fifth Assessment Report (AR5) of the Intergovernmental Panel on Climate Change (IPCC) shows that the globally averaged surface temperature of the earth and oceans has increased about $0.85^{\circ} \mathrm{C}\left[0.65-1.06^{\circ} \mathrm{C}\right]$ during the period 1880 to 2012. Therefore, global warming is inevitable (IPCC, 2013). The effects of global warming are closely related to the increase in the frequency and severity of extreme events such as floods, droughts, and heat and cold waves, rather than to changes in the average climate condition (Peterson et al. 2013). Changes in extreme events of temperature (ETI) affect many aspects of human life such as water resources (Xu et al. 2010), public health (Piticar et al. 2018), agriculture (Ju et al. 2013), energy (Añel et al. 2017), and mortality (Barnett et al. 2012). A period of consecutive days with very high and low temperatures is called a warm or cold wave (Cook et al. 2013). They are one of the forms of extreme climate events, and their frequency, intensity, and duration are expected to increase under climate change in the next decades. Increasing in frequency and intensity of temperature extremes is significant for detecting cold spells in the region with dry climates such as Iran, which depends on snowmelt water 
resources in the warm period of the year. Donat et al. (2013) showed that significant warming in all seasons is associated with more pronounced warming in cold seasons of the Earth.

Studies examining the minimum and maximum temperature of Iran using the output of CMIP5 (FallahGhalhari et al. 2019) and CMIP6 (Zarrin \& Dadashi-Roudbari, 2020) models have reported an increase in the minimum temperature, especially for the mountainous regions of Iran that it is a serious threat to Iran's water resources.

Therefore, the projection of extreme events, especially its seasonal cycles, has great importance in studies related to water resources, agriculture, and bioclimatology. The most essential tools for studying the future climate are general circulation models (GCMs). These models are also valuable to simulate the historical period. The output of general circulation models has also been used to project extreme events around the world and their output has been evaluated (Kharin et al. 2013; Sillmann et al. 2013; Wuebbles et al. 2014; Dong et al. 2015; Alexander \& Arblaster, 2017; You et al. 2018; Ongoma et al. 2018; Xu et al. 2019; Yu et al. 2020). However, what needs more attention regarding the use of GCMs is the high uncertainty of these models. To reduce model uncertainty, a new generation of these models called Earth System Models (ESM) is developed that involves interaction between different parts of the climate system (including the atmosphere, ocean, land ice, and sea) and the exchange of energy and mass (Knutti and Sedlacek, 2013). In this version of the models, chemical processes, land use, plant and ocean ecosystems as well as the carbon cycle, which allows the integration of biochemical processes in the Earth system, are included (Heavens et al. 2015). The ESM model series is the base of the Coupled Model Intercomparison Project (CMIP) (Carvalho et al. 2017). Despite this important achievement in the CMIP model series, there is still a great deal of uncertainty. Although the uncertainty may not be a big deal when looking into the values of annual or seasonal averages, it becomes a serious challenge when the goal is to study extreme events.

However, three strategies are proposed to reduce uncertainty: 1-Downscaling (dynamical or statistical approaches) (Manzanas et al. 2018); 2- Bias Correction (BC) (Navarro-Racines et al. 2020), and 3- multimodel ensemble approach (Tegegne et al. 2020). Dynamical downscaling methods are time-consuming, and because of the lack of hardware infrastructure in developing countries such as Iran, using this method is not efficient. Therefore, the multi-model ensemble (MME), and Bias-Correction methods are better choices adding more values. This is especially important when the MME is based on a biascorrected method, which significantly reduces the uncertainty. Another important point on the projection of temperature extremes (specifically hot and cold spells), is the lack of universal definition. Overviewing the literature shows that different researchers have mainly used three methods: 1- using an absolute threshold (for example, five consecutive days with a temperature between $30-35^{\circ} \mathrm{C}$ ) (Suparta and Yatim, 2017); 2- The use of percentile values (Kent et al. 2014) and 3- combined indices of different meteorological variables according to the guidelines approved by the World Meteorological Organization (WMO), such as Expert Team on Climate Change Detection and Indices (ETCCDI) (Alexander et al. 2006; WMO, 2010; Hong et al. 2018). In this research, the third approach has been used. 
The importance of temperature extremes has led to a wide range of studies. The review of the literature reveals that these studies can be methodologically divided into different categories. This included monitoring temperature using gauge data (Merlone et al. 2019; Sheridan et al. 2020), reanalysis dataset (Zhu et al. 2017; Donat et al. 2018; Sheridan et al. 2020), and satellite products (Mushore et al. 2018; Azarderakhsh et al. 2020), and projecting future climate. The methods of future projections of temperature extremes are extensive and can be divided into different categories based on a direct output of models (Alexander \& Arblaster, 2017; LUO et al. 2020), statistical downscaling (Ali et al. 2019; Yang et al. 2019), dynamical downscaling (Bozkurt et al. 2019; Zhu et al. 2020), studies based on Bias-Correction output (Gao et al. 2019; Xu \& Wang, 2019; Navarro-Racines et al. 2020) and MMEs (Tegegne et al. 2020; Tegegne \& Melesse, 2020). Temperature extremes of Iran have also been considered by many researchers in recent years. The main part of these studies is investigating them using gauge data (Rahimzadeh et al. 2009; Soltani et al. 2016; Rahimi \& Hejabi, 2018; Fallah-Ghalhari et al. 2019). Future climate projections also rely on downscaled datasets for a particular station or geographic area (Vaghefi et al. 2019; FallahGhalhari et al. 2019; Naderi et al. 2020).

A review of temperature extremes has shown that even though many global studies using gridded data, they have received less attention in Iran. Since Iran is a large area with a complex topography and has climate diversity, the use of grided data that can cover the entire area of the country compared to previous research that used only station data is an advantage of this research. Also, Bias-Correction and multimodel ensemble (MME) methods have been used for projecting temperature extremes in Iran for the first time.

This study aimed to project seasonality of ETIs by emphasizing TX, TN, WSDI, CSDI from ETCCDIs indices. Two newly introduced ETI including Maximum number of consecutive frost days (CFD) and the Maximum number of consecutive summer days (CSU), seasonality, and the CMIP5 BC MME approach are used for the first time in Iran.

Based on the purpose of this research, in the first step, the ensemble of selected CMIP5 Bias-Correction models is generated using the independence weighted mean (IWM) method. Then TX, TN, WSDI, CSDI, CFD, and CSU indices for the duration of cold and heat waves, frost, and summer days of Iran using two scenarios RCP4.5 and RCP8.5 are studied. The achievement of this study is very important for the fields of public health, water resources, and agriculture in Iran.

\section{Material And Methods}

\subsection{Study area and dataset}

Iran has an area of 1,648,195 which is located in southwest Asia with an arid and semi-arid climate (Fig. 1). one-third of Iran is covered by mountains, and most of its remaining parts are included of dry plains and deserts, and only less than a quarter of that is cultivable. The existence of mountain ranges such as Zagros and Alborz is associated with severe temperature fluctuations in Iran. In this study, using the 
CMIP5 Bias-Correction Data for the minimum and maximum temperature of Iran (1965-2005), we have shown that the minimum temperature in winter reaches $-8.53^{\circ} \mathrm{C}$, and the maximum reached $44.8^{\circ} \mathrm{C}$ in summer. Since most of Iran's agriculture is rainfed, and its freshwater resources are highly dependent on snowmelt, any variability in temperature, especially the increased heat waves, is associated with many issues for vulnerable water resources and agriculture of Iran..

\subsection{Observation dataset}

The observation dataset is the homogeneous time series of daily maximum and minimum temperatures of 40 synoptic stations (Fig. 1). The gauge data were obtained from the Meteorological Organization of Iran (IRIMO) (https://www.irimo.ir). The selected stations were subjected to strict quality control, which included identifying and correcting aberrant points in the long-term climate time series and covering the gaps. To ensure data quality, in the first stage, stations that had a large number of data gaps or were missing for at least 10 years were excluded. Then, the station dataset was analyzed for the presence of extreme data points, and data with more than four times the standard deviation value were excluded from the monthly averages. Station data were used only for evaluation of CMIP5 data with a 40-year time series (1965-2005) as shown in Fig. 1.

\subsection{CMIP5 Bias-Correction Multi models}

In this research, five CMIP5 BC MME were used. Both the minimum and maximum temperature indices are obtained from the Inter-Sectoral Impact Model Intercomparison Project (ISIMIP) archive for the first realization ('r1i1p1f1') (see Table 1). In the ISIMIP project for Bias-Correction of CMIP5 climate data, the data of EartH2Observe, WFDEI, and ERA-Interim data has merged to Bias-correct the ISIMIP (EWEMBI) (Lange, 2018).

The two periods 1965-2005 and 2021-2099 were considered as historical and projection periods, respectively. Also, two scenarios, representative concentration pathway (RCP) of RCP4.5 and RCP8.5, were selected to project extreme temperatures in Iran.

Table1. CMIP5 Models were supplied by the Inter-Sectoral Impact Model Intercomparison Project (ISIMIP) archives were used in this research 


\begin{tabular}{|c|c|c|c|}
\hline Model name & $\begin{array}{l}\text { SPATIAL/TEMPORAL } \\
\text { resolution }\end{array}$ & Research Centre & References \\
\hline $\begin{array}{l}\text { MIROC-ESM- } \\
\text { CHEM }\end{array}$ & $0.5^{\circ} \times 0.5^{\circ} /$ daily & $\begin{array}{l}\text { Japan Agency for marine-E arth } \\
\text { Science and Technology (JAMSTEC), } \\
\text { Atm osphere and Ocean Research } \\
\text { Institute (AORI), and National } \\
\text { Institute for E nvironm ental Studies } \\
\text { (NIES), (JAMSTEC, Japan) }\end{array}$ & $\begin{array}{l}\text { Watanabe et al. } \\
\text { (2011) }\end{array}$ \\
\hline HadGEM2-ES & $0.5^{\circ} \times 0.5^{\circ} /$ daily & $\begin{array}{c}\text { Met Office Hadley Center (UK Met } \\
\text { Office, UK) }\end{array}$ & Collins et al. (2008) \\
\hline $\begin{array}{l}\text { IPSL -CM5 A- } \\
\text { LR }\end{array}$ & $0.5^{\circ} \times 0.5^{\circ} /$ daily & $\begin{array}{l}\text { L'Institut Pierre-Sim on Laplace (IPSL, } \\
\text { France) }\end{array}$ & Boucher (2018) \\
\hline G FDL-E SM2M & $0.5^{\circ} \times 0.5^{\circ} /$ daily & $\begin{array}{l}\text { National Oceanic and Atm ospheric } \\
\text { Adm inistration (NOAA, USA) }\end{array}$ & Dunne et al. (2012) \\
\hline NorESM1-M & $0.5^{\circ} \times 0.5^{\circ} /$ daily & $\begin{array}{c}\text { Norwegian Climate Centre (NCC, } \\
\text { Norway) }\end{array}$ & Iversen et al. (2013) \\
\hline
\end{tabular}

In this paper, CSDI and WSDI indices were used for assessing spell length duration (Moss et al. 2010) in Iran (Table 2). The World Meteorological Organization Commission on Climatology (CCl) and the Climate Variability and Prediction (CLIVAR) Expert Team on Climate Change Detection and Indices (ETCCDIs) jointly developed a core set of indices (Anandhi et al. 2016). In these indices, spells end in each season and do not continue to the next season on a seasonal scale. Thresholds of 90th and 10th percentiles of Tmax and Tmin for each day of each season of the year were calculated using the method described by the ETCCDIs. (Zhang et al. 2009).

Table 2. Definitions of 2 spell duration indices (SDI)

\begin{tabular}{|c|c|c|c|}
\hline Indices & Name & Units & Description \\
\hline CSDI & $\begin{array}{l}\text { Cold spell } \\
\text { duration } \\
\text { index }\end{array}$ & day & $\begin{array}{l}\text { The num ber of days per season with at least } 6 \text { consecutive days when } 7 \\
<\mathrm{TN} 1^{0 \mathrm{ta}} \text {, where } \mathrm{TN} \text { is the daily minim um temperature and } T \mathrm{~N}^{10 \mathrm{th}} \text { is } 1 \\
\text { calendar day }{ }^{10 \mathrm{tan}} \text { percentile. }\end{array}$ \\
\hline WSDI & $\begin{array}{l}\text { Warm spell } \\
\text { duration } \\
\text { index }\end{array}$ & day & $\begin{array}{l}\text { The num ber of days per season with at least } 6 \text { consecutive days when }] \\
>\mathrm{TX}^{90 \mathrm{th}} \text {, where } \mathrm{TX} \text { is the daily maxim um temperature and } \mathrm{TX}^{90 \mathrm{th}} \text { is } 1 \\
\text { calendar day }{ }^{90 \mathrm{th}} \text { percentile. }\end{array}$ \\
\hline
\end{tabular}

\subsubsection{Assessing the precision of the Climate models}

The Taylor diagram is applied to highlight the preciseness of different models in comparison with observations. This method shows the changes in the observed values compared to the modeled value according to the standard deviation and Root-Mean-Square Deviation (RMSD) (Kumar et al. 2014).

\subsubsection{Independence Weighted Mean (IWM)}

The analysis of individual models does not provide suitable results due to their high uncertainty. Also, these results are not proper for adaptation and adjustment policies and make the research too theoretical 
rather than directing it to a practical field. In this regard, we used the output of 5 selected CMIP5 BiasCorrection models, the details of which are given in Table (1), using a Multi-Model Ensemble (MME) method called Independence Weighted Mean (IWM). This method was developed by Bishop \& Abramowitz (2013). For further reading see Bishop \& Abramowitz. (2013) and Bai et al, (2020).

\subsubsection{Mean of daily Minimum and maximum temperature (TN \& TX)}

To demonstrate the long-term changes of the minimum and maximum temperatures of Iran during the historical period (1965-2005) and the projected future period (2021-2060 and 2061-2061), the mean minimum (TN) and maximum (TX) data of the CMIP5 BC MME were used (Table. 3). These two indices are widely used for studies related to climate variability and change and are the main input data for calculating ETIs.

\section{Table 3. Definition of the minimum (TN) and maximum (TX) temperature}

\begin{tabular}{llll}
\hline Indices & Name & Units & Description \\
\hline TN & $\begin{array}{l}\text { Mean of daily minimum } \\
\text { temperature }\end{array}$ & ${ }^{\circ} \mathrm{C}$ & $\begin{array}{l}\text { Mean value of TN over Season, where TN is the daily minim } \\
\text { temperature. }\end{array}$ \\
TX & $\begin{array}{l}\text { Mean of daily maximum } \\
\text { temperature }\end{array}$ & ${ }^{\circ} \mathrm{C}$ & $\begin{array}{l}\text { Mean value of TX over Season, where TX is the daily maxim } \\
\text { temperature. }\end{array}$ \\
\hline
\end{tabular}

\subsubsection{Maximum number of consecutive frost and summer days (CFD and CSU)}

The ETCCDI climate indices have been the subject of a lot of research in recent years, and as mentioned in the introduction, many studies of the ETIs have been conducted in Iran, both for observation (Rahimzadeh et al. 2009; Darand et al. 2015; Soltani et al. 2016; Rahimi \& Hejabi, 2018; Fallah-Ghalhari et al. 2019; Vaghefi et al. 2019) and the projected period (Darand, 2020; Naderi, 2020). As mentioned in the introduction, Iran is stretched between 25 to 40 degrees north and it does have mountain ranges such as Alborz and Zagros, it is obvious that experiences frost days $\left(\mathrm{TN}<0^{\circ} \mathrm{C}\right)$ in the cold period of the year (winter and Autumn) and summer days ( $\mathrm{TX}>25^{\circ} \mathrm{C}$ ) in the warm period of the year (spring and summer). These two indices, also known as FDO and SU25, are the main indicators of ETCCDIs for temperature (Alexander et al. 2006), which are investigated in most studies on an annual scale. Although these two indices and their changes are very important, it is clear that frosty days occur in mountainous areas and their existence is necessary even to eliminate pests in the cold period of the year and prevent extensive infestations. However, these two indices should be considered as a risk when they occur on consecutive days and can be recognized as a serious risk by examining the maximum number of consecutive days. Accordingly, two new indices called the Maximum number of consecutive frost days (CFD) and the Maximum number of consecutive summer days (CSU) was used on a seasonal scale. The results of these two indices are widely used in various sectors, including energy, water resources, drought stress, optimal growth crops and frost damage, and transportation. Table (4) provides a complete explanation of these two new indices. 
Table 4. Indices of Maximum number of consecutive frost and summer days

\begin{tabular}{|c|c|c|c|}
\hline Indices & Name & Units & Description \\
\hline CFD & $\begin{array}{l}\text { Maximum number of } \\
\text { consecutive frost days }\end{array}$ & day & $\begin{array}{l}\left.\text { The longest period of consecutive days when } \mathrm{TN}<0^{\circ} \mathrm{C} \text {, where }\right] \\
\text { is the daily minim um temperature }\end{array}$ \\
\hline $\mathrm{CSU}$ & $\begin{array}{l}\text { Maximum number of } \\
\text { consecutive summer days }\end{array}$ & day & $\begin{array}{l}\left.\text { The longest period of consecutive days when } \mathrm{TX}>25^{\circ} \mathrm{C} \text {, where }\right] \\
\text { is the daily max imum tem perature }\end{array}$ \\
\hline
\end{tabular}

\section{Discussion}

\subsection{Minimum and maximum temperature validation of selected CMIP5 Bias-Correction models in Iran using the Taylor diagram}

The Taylor diagram provides a statistical summary of the correlation between CMIP5 simulations and observation data in terms of correlation (R), a root-mean-square difference (RMSD), and the ratio of model variances (Taylor, 2001). Therefore, we used the Taylor diagram to investigate spatial distribution agreement between observation and CMIP5 simulation for the minimum and maximum temperature of Iran during the period 1965-2005 (Fig. 2). In the presented diagrams, the correlation between CMIP5 simulations for the minimum and maximum temperature of Iran and observation is shown by the Azimuthal position from the test field. As mentioned, we have evaluated five climate models MIROC-ESMCHEM, HadGEM2-ES, IPSL-CM5A-LR, GFDL-ESM2M, and NorESM1-M from the CMIP5 Bias-Correction models. Then the ensemble of these models is applied to study the seasonal ETI changes in Iran using the Independence Weighted Mean (IWM) method. The validation results of 5 CMIP5 Bias-Correction models and the generated ensemble model by the IWM method showed that GFDL-ESM2M and HadGEM2-ES models represented the highest performance for the average of the whole of Iran. In contrast, NorESM1-M and IPSL-CM5A-LR models showed lower performance than other single models in Iran for both minimum temperature (Fig. 2) and maximum temperature (Fig. 2), respectively.

As shown in figure (2), the generated ensemble models using the IWM method have significantly reduced the bias compared to individual models in Iran. For example, as shown in Figure (3) for maximum temperature, in autumn, the IPSL-CM5A-LR GCM has the lowest correlation with 0.87 and the GFDLESM2M GCM has the highest correlation with 0.91 in the area-averaged for Iran. The ensemble model has increased the correlation to 0.96 , which clearly shows how much the applying of the ensemble model decreases the bias in projecting future periods. The same is observed for the minimum temperature of autumn. The NorESM1-M model has shown the lowest correlation (0.86) for the minimum temperature with a slight difference compared to the IPSL-CM5A-LR model. The GFDL-ESM2M model has shown the highest correlation (0.91) among them.

As shown in the diagram, the ensemble model with a correlation of (0.94) has greatly reduced the bias. The same result is true for other seasons, which were also shown in the relevant diagrams. In many studies, the higher performance of MME compared to individual models has been reported. For example, Reyers et al. (2016) examined 22 models in Europe and concluded that single models for wind provide different results whereas the ensemble model shows higher performance. Also, the higher performance of 
ensemble models is approved in the Northeast China Plain with 28 Global Climate Models (GCMs) for rice yield (Zhang et al. 2019), Peninsular Malaysia (Noor et al. 2019), global ETI of CMIP6 (Kim et al. 2020), Pakistan rainfall and temperature (Ahmed et al. 2020) and South Asia drought projection (Zhai et al. 2020). Therefore, the results represent that the minimum and maximum temperature using MME models added a higher value to the output compared to applying individual models in Iran (Fallah- Ghalhari et al. 2019; Darand, 2020; Rahimi et al. 2020; Zamani et al. 2020; Naderi, 2020; Kamyar et al. 2020).

\subsection{Seasonal variations of TN, TX, CSDI, WSDI, CFD, and CSU}

Seasonal changes of six temperature indices studied in Iran during the historical period of 40 years (1965-2005) based on the output of CMIP5 MME models were shown in Figure (4). Except for the TX and TN which are measured in degrees Celsius, four other indices represent duration, which is measured in days. Our results show that the minimum seasonal temperature is at least -5.53 and at most $28^{\circ} \mathrm{C}$ in Iran. In summer, Dasht-e-Lut and Dasht-e-Kavir deserts are known as the main hot spots of TX and TN, with temperatures above $25^{\circ} \mathrm{C}$ for minimum and more than $40^{\circ} \mathrm{C}$ for maximum. In the other seasons, the main sources of high temperatures for these two indices are southwest, south, and southeast of Iran. The reason for the very high maximum and minimum temperatures in the eastern half of Iran is the continental climate, being away from moisture sources and various geographical features. Desert surfaces and clear skies on the one hand cause a large increase in temperature, especially in the warm period of the year, and on the other hand increase the coefficient of variation of temperature.

In winter (DJF) for both TX and TN indices, the temperature has an increasing gradient from northwest to southeast of Iran. In spring, the minimum temperature is $-0.55^{\circ} \mathrm{C}$ and the maximum temperature is $10.3^{\circ}$ C. In the northwestern and western regions, the maximum and minimum temperatures in spring are lower than in other regions of Iran. In this season, with the arrival of cold systems from the northwest and their rapid propagation in the northwest-southeast direction (location of the Zagros Mountain range) and finally, the accumulation of cold air due to the roughness of the Zagros Mountain range reduces the minimum temperature and maximized.

In summer (JJA), with the increase of day length in the northern regions of Iran, along with the increase of extensive subsidence of air, the temperature becomes more uniform and the variability of minimum and maximum temperatures is less than other seasons.

The daily minimum temperature (TN) in summer is $8.37^{\circ} \mathrm{C}$ and the maximum value of the same index is $28^{\circ} \mathrm{C}$. In contrast, for daily maximum temperature $(\mathrm{TX})$ the minimum and maximum values are $25.6^{\circ} \mathrm{C}$ and $44.8^{\circ} \mathrm{C}$, respectively. Atmospheric systems originating in the southern regions of Iran such as Arabian anticyclone and subtropical high (STH) are the main cause of temperature increase in summer and play an important role in increasing the maximum temperature in summer in southern regions of Iran.

According to the results of the $5 \mathrm{CMIP} 5 \mathrm{BC}$ MME, the maximum temperature reaches $44.8^{\circ} \mathrm{C}$ in summer in southwestern Iran. It should be noted that this value is the 40-year average of the maximum daily temperature, however, if its frequencies are examined, the maximum temperature will be higher. 
By comparing the figures of maximum temperature in spring and summer from south to north, we can see the impact of the northward movement of subtropical high pressure from spring to summer on temperature changes. In autumn (SON), the minimum temperature (TN) in the highlands of Iran has shown less than $5^{\circ} \mathrm{C}$. Changes in the minimum and maximum daily temperature range have shown that the temperature in Iran has many complexities and the interaction between local factors and atmospheric circulation systems cause many changes in the spatial patterns of temperature in Iran.

The study of changes in the two indices of TX and TN during the four seasons shows that they are the highest in all seasons on the southern coast of Iran. However, there is one exception in the summer, as the TX index doesn't show the highest values in the southern coasts of Iran in summer. This may be due to the transfer of humidity caused by the Asian summer monsoon (ASM) in southeastern Iran and the strengthening of sea breeze to land. The two indices WSDI and CSDI represent the warm and cold spells of Iran, respectively, and can be suitable indices for seasonal evaluating cold and heat waves during the historical period (1965-2005) using the output of MME (Fig. 4).

According to the description of the indices TX and TN, which are the two indices of WSDI and CSDI, they presented a completely symmetrical pattern for Iran. Cold spells of Iran in winter vary between 1.32 to 4.09 days and as expected, the western regions, the Alborz Mountain range in the north and northwestern Iran, showed the highest CSDI index. Minimum CSDI is observed on the southern coast of Iran in all seasons.

The maximum value of the CFD index is seen in the highlands of northwest, west, north, and northeast. The maximum CFD in winter is 89.3 days and the minimum index in terms of the seasonal cycle is observed in summer.

In spring, the maximum amount of CFD is limited to the northwest and highlands of Alborz in the north of Iran. The southern coasts do not experience CFD in any season. this index is limited to small parts of northwestern and western Iran in summer. Another index that has been used in this research for the first time on a seasonal scale is the CSU index i.e the maximum number of consecutive summer days. Except for a few limited areas on the Caspian coast, this index is not observed in winter above latitude $36^{\circ} \mathrm{N}$. The Zagros Mountains are another area that does not experience CSU in winter. CSU index is mostly observed in winter on the coast of the Oman Sea by the maximum value of 20.8 days.

In spring and with increasing air temperature in Iran, the CSU value is subjected to at least half a day ( 0.52 days) in the northwestern, western, and northeastern regions of Iran. While the maximum of 80.3 days is seen on the coast of the Oman Sea. In summer, as mentioned above, due to the subtropical high (STH) presence in most parts of Iran, the CSU reaches 92 days. In other words, except for northwestern Iran, which experiences only 25 days of CSU summer, all summer days in the rest of the country are associated with CSU.

In autumn, the CSU decreases sharply, and the index reaches 5.76 days. In contrast, summer conditions are still prevailing in the southern regions of Iran. The value of the CSU index in this region reaches 87.7 
days, and the conditions of summer days are observed in the coast of the Oman Sea to the Dasht-e Lut in central Iran and on the entire coast of the Persian Gulf.

\subsection{The anomaly of projected CSDI}

Projected changes in the CSDI index in Iran for the near future (2021-2060) and far future (2061-2100) under the RCP4.5 and RCP8.5 scenarios have shown a completely negative anomaly of the CSDI index compared to the historical period (1965-2005). CSDI negative anomaly is increasing from north to south and from east to west of Iran. The coasts of the Persian Gulf and the Oman Sea in all seasons, periods, and studied scenarios are the main hot spot of Iran's cold spell. Based on projected results in winter (DJF), the CSDI index in Iran will decrease between - 0.31 to -2.88 days for the near future period (20212060) based on the RCP4.5 scenario (Fig. 5).

in winter, the index has shown a one-day increase for the minimum and maximum values in the far future compared to the near future period. So that the minimum of the index with -1.02 day and a maximum of that with 3.80 day decrease in future. The results of the (RCP8.5) scenario also showed that in the winter the cold spells in the near future and the far future will decrease by a maximum of 3.34 and 4.09 days, respectively.

In winter, the cold spells decrease for more than 2 days on the southern coasts of Iran. The minimum of cold spells anomaly is seen in the northeast, northwest, and east of Iran.

In the spring (MAM) projected cold spells showed that the coasts of the Persian Gulf and the Oman Sea have shown a decrease of more than 3 days in all periods for two scenarios. Similar anomalies have also been observed in northeastern Iran in the spring (Fig. 5).

By the end of this century, based on the results of RCP8.5, cold spells in northwestern Iran have shown an anomaly of -0.75 , which does not reach even one day. Therefore, global warming will have the least impact on northwestern Iran.

In the summer (JJA) the downward trend of cold spells reaches its maximum magnitude. In this season, CSDI will decrease between -2.05 to -5.71 days compared to the historical period (1965-2005). The RCP8.5 result also showed minimum and maximum anomalies of -2.23 and -5.79 days. In the far future, the magnitude of negative anomaly would increase in the southern and southwestern regions of Iran. The eastern regions, and the Alborz and Zagros Mountain ranges experience the least negative anomaly of cold spells in Iran. The spatial pattern of CSDI anomaly in summer has shown that the coasts of the Persian Gulf are the main hot spot of this index in Iran. Unlike other seasons, in summer (JJA), Urmia Lake Basin has shown a significant downward trend for the CSDI index. This is a serious threat to the ecosystems of Lake Urmia in the coming decades (Fig. 5).

In autumn (SON), CSDI has presented a homogeneous spatial pattern, so that below the latitude $35^{\circ} \mathrm{N}$ negative anomaly of cold spells reaches more than 2 days. By contrast, northwest Iran has shown the minimum anomaly of CSDI by one day/year (Fig. 5). In autumn (SON) as well as winter (DJF), the coasts 
of the Persian Gulf and the Oman Sea are the main hot spots of cold spells decrease in Iran. The decreasing CSDI in all seasons is a serious threat to water resources, agriculture, and pest growth.

\subsection{The anomaly of projected WSDI}

Investigating seasonal warm spells of Iran shows an increasing trend in the whole country under the projected scenario. Positive WSDI anomaly is increasing from north to south in Iran (Fig. 6). Identified areas that are the main hot spots of cold and warm spells, showed that the decreasing cold spells in winter correlated well with increasing warm spells.

The results showed that warm spells in winter show a significant increasing trend, so it is expected that winters will be warmer in the coming decades. In the analysis of the mean time series of CSDI and WSDI, it is found that warm spells are more common than cold spells, especially in winter. Since CSDI and WSDI indices are computed from TX and TN temperature indices (10th and 90th percentiles), it means that very hot days will be more frequent than very cold days in the future. In this regard, Im et al. (2017) by examining the heat waves of Asian countries, concluded that heatwaves will occur every 10 to 20 days at the end of this century and the coastal cities of southern Iran, Dubai, Abu Dhabi, and Doha are greatly affected by this event. They also showed that the wet-bulb temperature (TW) reached near $35^{\circ} \mathrm{C}$ in the summer of 2015 in the port of Mahshahr (Iran), on the coasts of the Persian Gulf and in Saudi Arabia, indicating that the threshold was broken earlier than expected (Schär et al. 2016). Confirming the previous research (Schär et al. 2016; Im et al. 2017), the results of our study showed the increase of thermal stress in the southern regions of Iran in the coming decades.

The anomaly of projected warm spells in winter (DJF), which is examined using the WSDI, has shown a significant increase over Iran. The anomaly hotspot of WSDI in winter is the coasts of the Oman Sea in southeastern Iran. Based on the RCP4.5 scenario, WSDI will have an anomaly of 3.24 to 16.4 days in the near future (2021-2060). While in the far future (2061-2100), the number of days will be doubled for warm spells and according to the results of the RCP4.5 scenario, the maximum index reaches 35.5 days (Fig. 6).

The projected results using the RCP8.5 scenario show that warm spells will increase to a minimum of 4.22 days in the near future and 15.9 days in the far future. the maximum of 25.3 days and 64.6 days is projected to increase in the near and far future, respectively.

In the spring (MAM), the warm spells projected a maximum increase of 59.8 days by the end of this century. In contrast to winter, when only the coasts of the Oman Sea showed the main spot of WSDI, in spring the coasts of the Persian Gulf will also show a significant increasing trend. The northern regions, the northeast, and the northwest of Iran will experience a maximum increase of 14.5 days in the far future under the scenario RCP8.5 (Fig. 6). Warm spell events in the near future will increase by a maximum of 2 days compared to the historical period according to the RCP4.5 scenario.

In summer (JJA), we see a completely different spatial anomaly pattern of WSDI in Iran. In this season, the eastern regions of Iran along with the northern and northwestern regions showed the least increase in 
the frequency of warm spells. Unlike the CSDI index, which showed the maximum negative anomaly on the coast of the Persian Gulf, this region is the main hotspot of positive anomaly warm spells in Iran in this season. At the end of the century, under the RCP8.5 scenario, the frequency of warm spells will increase by about 80 days, which will be a serious threat to the inhabitants of this region. In the far future $(2100-2061)$ according to the RCP8.5 scenario, the frequency of warm spells will increase at least 41 days across Iran.

In the autumn season (SON), from the Strait of Hormuz to the west, we see severe anomalies of warm spells. This significant increase, based on the results of the RCP8.5, reaches 72.9 days in the period 2061-2100, which is 7.4 days longer than in summer. In this season, the northeastern regions and the southern coast of the Caspian Sea show the least WSDI anomaly. The results showed that warm spells will increase in the future in terms of frequency and duration. In the cold seasons of the year (winter and autumn), warm spells will have more intensity and frequency. In the southern coasts of Iran, warm spells are more persistent. The number of days with WSDI $>20$, covers a smaller percentage of the area of Iran despite its significant intensity (Fig. 6). In contrast, the frequency of WSDI $<20$ is seen in most parts of Iran. The frequency of warm spells is higher in the southern, southeastern, southwestern, and central coasts of Iran.

The geographical distribution of warm spells in Iran showed that its hotspots are generally found in the southern regions of Iran, especially on the coast of the Persian Gulf and the Sea of Oman. Also, the increase of warm spells in the Zagros Mountain range is more than Alborz Mountain. This increase of warm spells is very important for the life of Iran's main rivers such as Karun, Karkheh, Zayandeh-Rud, etc., which can pose significant threats to Iran's energy (hydropower), agriculture, and water resources sectors. The rising temperature trend in the mountainous and snow-covered regions of the Zagros is larger than the northern regions of Iran, and their annual snow reserves will melt faster in the future. Globally (Pepin et al. 2015) as well as numerous regional studies (for example Andean Mountain range (Vuille et al. 2015) and Tibetan Plateau (You et al. 2018)) it is shown that Mountains are warming faster than the global average. In this regard, Fallah-Ghalhari et al. (2019) and Zarrin and Dadashi-Roudbari (2020) reported an increase in temperature across Iran especially in the highlands of western and northwestern it by the end of the century.

\subsection{Seasonal projection of CFD in Iran}

The projected changes of the CFD are shown in Figure (7). The CFD index is a general indicator of frost damage. As mentioned earlier for the historical period; all studies conducted in Iran (Rahimzadeh et al. 2009; Soltani et al. 2016; Fallah-Ghalhari et al. 2019; Darand, 2020) used the FD0 index, which provided general information on changes in frost days throughout the year. The results of seasonal projection for the two periods 2021-2060 and 2061-2100 showed that the anomaly of CFD index is negative in all seasons of the year based on two scenarios RCP4.5 and RCP8.5. Since there are more frosty days in winter, the anomaly of this index is more in this season. 
The CFD anomaly in this season is between -0.03 to -16.1 days/year ${ }^{-1}$ based on the results of the RCP4.5 scenario in the near future compared to the historical period (1965-2005). The maximum anomaly is observed in the interior mountain, Zagros, Alborz, and the northeastern mountain of Iran. In all seasons, the southern, southeastern, and southwestern coasts of Iran and most parts of central Iran show minimal CFD anomalies. The reason for this is either the lack of CFD during the historical period in seasons such as summer in large parts of Iran or is the fact that these areas did not have CFD in the historical period. In the far future, according to the results of RCP4.5, the CFD index will decrease by a minimum of 1.1 and a maximum of 24.4 days, and the maximum of this reduction anomaly is observed in the Zagros Mountain. According to the RCP8.5 scenario, the index has decreased by 20.6 and 38.1 days for the periods 2021-2060 and 2061-2100, respectively (Fig. 7).

In the spring (MAM), the results of the RCP4.5 scenario show that during two study periods, the CFD anomaly in Iran is a maximum of 10 days. CFD will decrease in the western and northwestern highlands of Iran during the near and far future period by a maximum of 6.39 and 9.65 days. The central, eastern, and southern regions of Iran in this season either do not have consecutive frost days or are very few if any. The results of the RCP8.5 scenario for CFD in Iran showed a decrease of 15.7 days in the far future (Fig. 7). The result is consistent with previous studies (Fallah-Ghalhari et al. 2019) that compared the minimum and maximum temperatures in Iran.

In the summer (JJA), as mentioned, we see CFD in almost a few places in Iran. Therefore, large parts of Iran will not have CFD in the future. The only areas that showed CFD anomalies for Iran in the summer are the western and northwestern highlands of Iran with 0.5 days. The results for the autumn (SON) showed that like other seasons and especially in comparison with the winter season (DJF), CFD in Iran has a completely decreasing anomaly. The large CFD anomalies are seen in the Alam-Kuh highlands in northern Iran, Lalehzar in southern Iran, and Kuh-e Dinar in the Zagros Mountains. The maximum anomaly of the RCP4.5 scenario is 7.8 days and the RCP8.5 scenario is 11.9 days (Fig. 7). In autumn, except for the mentioned regions, CFD anomaly is less than 5 days in other regions of Iran. The summary of the results of this section shows that the frost days and especially the maximum consecutive frost days in Iran will decrease in the coming years. This reduction has already been confirmed by many studies examining Iran's FD0; As Darand et al. (2015) using the Iranian climatic database during 19622004, also reported a decreasing trend for frost days. Also, Fallah-Ghalhari et al. (2019) reported a decreasing trend for frost days in Iran during 1976-2005 using the records of 45 ground stations in Iran, which confirms the results of this study. At the regional scale, Kouzegaran et al. (2019) using ground station data showed a decreasing trend for FD0 in Central Khorasan in northeastern Iran during 19911995.

\subsection{Seasonal projection of CSU in Iran}

Investigating the winter (DJF) consecutive summer days it is found that CSU on the coast of the Oman Sea in southeastern Iran during the two periods 2021-2060 and 2061-2100 under two scenarios RCP4.5 and RCP8.5 will experience a significant increasing trend. Except for the above-mentioned region, other parts of Iran have shown CSU anomalies of less than 10 days. The CSU maximum for the near future 
2021-2060 is 12.7 days and is 26.4 days for the far future under the RCP4.5 scenario. It is 21.1 and 42.6 days for the near and far future under the RCP8.5 scenario, respectively. What is interesting about Iran's CSU is the significant increase in summer days in winter for the southern and southeastern regions of Iran. The maximum summer days of Iran in winter (DJF) are even longer than spring (MAM) and autumn (SON). In contrast, regions with increasing CSU longer than 10 days in spring and autumn, are seen in more than $90 \%$ of the total area (exactly $93.54 \%$ ) of the country (Fig. 8).

In the spring (MAM) as shown in Figure (8), the maximum CSU covers all areas below the $36^{\circ} \mathrm{N}$. Unlike other seasons, the coast of the Persian Gulf shows the maximum CSU values. This result shows that the transitional seasons (spring and autumn) will disappear in the coming decades in the southern regions of Iran and the summer season will be longer. Projections show an increase of at least 1.04 days and at most 28.6 days for CSU in Iran. The minimum anomaly of CSU is observed in spring in the northwestern regions of Iran (Fig. 8).

In summer (JJA) we see a different spatial distribution of CSU in Iran. In this season, the northwestern region experiences a positive anomaly of CSU. According to the results of the RCP4.5 scenario, summer days will increase by about 25 days in the period 2021-2060 in this region of Iran. At the end of the century, this index reaches 47.9 days according to the results of RCP8.5 (Fig. 8). This unprecedented increase in CSU is a major threat to Lake Urmia, which has been revitalized in recent years and may reenter the landlocked period of this strategic lake in the not-too-distant future. On the other hand, this region is the agricultural hub of Iran and the CSU index can provide valuable information for drought stress and optimal plant growth.

The Autumn season (SON) has shown many changes compared to winter (DJF) and spring (MAM) seasons in Iran. In this season, the coast of the Persian Gulf in southwestern Iran and the coast of the Oman Sea in southeastern Iran show the minimum anomaly of CSU. This result is not far from the expectation because these areas are among the hottest areas of Iran with high CSU and according to previous findings (Zarrin and Dadashi Roudbari, 2020), with global warming, the temperature-based extreme indices will increase in Iran higher latitudes, especially in the mountainous regions of the country. Eastern regions, Central Iran, Zagros Mountains, West and North-West of Iran show an increase of 10 to 27.8 days for this season in Iran (Fig. 8). This increase in the high single free-standing mountain of the Iran southern latitudes is a serious threat to water resources because as the temperature warms, we will see a decrease in snowfall and also it's rapid melting in this region of Iran.

\subsection{The seasonal anomaly of extreme temperature indices (ETI) in Iran}

For a more detailed analysis of the six indices studied in Iran during different seasons, the anomaly of each index was computed for the country-wide area-averaged and its results are presented in Table (9). The results indicate that except for two indices, CFD and CSDI, which are representative of the maximum number of consecutive frost days and cold spells, other indices show positive anomalies for all studied seasons and periods. The TN index for the average of Iran reaches $0.43^{\circ}$ in near future (2021-2060) and 
$7.60^{\circ}$ in the far future (2061-2100) for winter (RCP4.5) and summer (RCP8.5), respectively. In other words, winter will have the lowest increase, and summer will have the highest increase for TN in Iran.

The results of the TX index are the same as TN. Our studies showed that the maximum daily temperature in Iran will increase by at least $1.66^{\circ}$ and at most by $6.11^{\circ}$ by the end of the century. As mentioned, CFD is one of the six studied indices, the anomaly of which will be negative for the country-wide average in the future. The cold seasons of the year (DJF and SON) show the greatest decrease for CFD according to the Iran climate.

In winter, according to the results of the RCP4.5 scenario, the value of CFD will decrease by 5.46 days in 2021-2060. At the end of the century, according to the results of the RCP8.5 scenario, we will see a significant decrease of CFD by 13.43 days. The CSU index is also examined to better understand the effects of global warming on Iran's climate. An interesting point for the CSU index is the increase in the anomaly of this index for the transition seasons of the year (MAM and SON). At the end of the century, under the RCP4.5 scenario, this index will increase by 11.35 days in spring (MAM) and 14.12 days in autumn (SON). The same conditions according to the RCP8.5 scenario will be 18.79 days and 20.51 days, respectively (Fig. 9). In other words, it can be said that the spring and autumn seasons are shortening in Iran. In contrast, the length of summer is increasing (Fig. 9 and Table 5). The two indices CSDI and WSDI, which represent the cold spells and warm spells of Iran, also show the decrease of cold spells and warm spells. On a seasonal scale, Iran's cold spells are decreasing at a rate of 3 days/season.

Iran's warm spells also showed a significant increase for the autumn (SON) and summer (JJA). The minimum increase in WSDI in winter with at least 7.22 days under RCP4.5 is observed in the near future (2021-2060). In contrast, the maximum WSDI with a maximum of 62.67 days will experience in the far future (2061-2100) under the RCP8.5 scenario (Fig. 9). Globally, many studies have reported an increase in temperature period indices and a decrease in cold and frost indices using CMIP5 models. Examples include research in the United States (Barnett et al. 2012), Mainland China (Ying et al. 2020), South Asia (Ullah et al. 2020), and the Middle East - North Africa (MENA) (Ntoumos et al. 2020). Therefore, it can be acknowledged that global warming in Iran will be very intense in the coming years and this increasing intensity will be significant for indices related to duration. 
Table 5

The seasonal average anomaly of selected ETI indices of Iran based on CMIP5 BC MME results

\begin{tabular}{|c|c|c|c|c|}
\hline \multicolumn{5}{|c|}{ Mean of daily minimum temperature (TN) } \\
\hline Season & RCP4.5-TS1 & RCP4.5-TS2 & RCP8.5-TS1 & RCP8.5-TS2 \\
\hline DJF & 0.43 & 0.64 & 0.63 & 1.88 \\
\hline MAM & 1.58 & 2.41 & 2.04 & 4.46 \\
\hline JJA & 4.06 & 5.01 & 4.59 & 7.60 \\
\hline SON & 2.12 & 3.06 & 2.58 & 5.49 \\
\hline \multicolumn{5}{|c|}{ Mean of daily maximum temperature (TX) } \\
\hline DJF & 1.66 & 2.99 & 2.33 & 5.00 \\
\hline MAM & 2.02 & 3.13 & 2.49 & 5.32 \\
\hline JJA & 2.50 & 3.59 & 2.89 & 6.11 \\
\hline SON & 2.45 & 3.73 & 2.90 & 5.94 \\
\hline \multicolumn{5}{|c|}{ Maximum number of consecutive frost days (minimum temperature $<0$ degrees_C) (CFD) } \\
\hline DJF & -5.46 & -8.08 & -7.19 & -13.49 \\
\hline MAM & -1.39 & -1.91 & -1.74 & -2.98 \\
\hline JJA & -0.001 & -0.001 & -0.001 & -0.001 \\
\hline SON & -1.42 & -2.01 & -2.85 & -3.93 \\
\hline \multicolumn{5}{|c|}{ Maximum number of consecutive summer days (temperature > 25 degrees_C) (CSU) } \\
\hline DJF & 1.36 & 2.77 & 1.98 & 6.29 \\
\hline MAM & 7.69 & 11.35 & 8.84 & 18.79 \\
\hline JJA & 4.02 & 5.05 & 4.41 & 6.10 \\
\hline SON & 9.70 & 14.12 & 11.04 & 20.51 \\
\hline \multicolumn{5}{|c|}{ Cold-spell duration index (CSDI) } \\
\hline DJF & -1.34 & -2.05 & -1.58 & -2.36 \\
\hline MAM & -1.51 & -1.71 & -1.54 & -1.96 \\
\hline JJA & -3.13 & -3.34 & -3.26 & -3.43 \\
\hline SON & -2.98 & -3.17 & -3.02 & -3.33 \\
\hline
\end{tabular}




\begin{tabular}{|lllll|}
\hline \multicolumn{4}{|l|}{ Mean of daily minimum temperature (TN) } \\
\hline DJF & 7.22 & 16.04 & 11.26 & 35.55 \\
MAM & 6.22 & 13.57 & 9.48 & 31.22 \\
JJA & 18.90 & 33.79 & 24.96 & 62.67 \\
SON & 15.99 & 28.99 & 19.96 & 49.26 \\
\hline \multicolumn{2}{l}{ Representative Concentration Pathway (RCP); TS1: 2021-2060; TS2: 2061-2100 } \\
\hline
\end{tabular}

To better capture the long-term changes in ETI in Iran, CSDI and WSDI, which are the most important and reliable indices for measuring the length of the hot and cold period, were selected and the area-averaged trend was examined across the country from 1965 to the end of 21 st. The results showed that CSDI is decreasing with a very steep slope in all seasons of Iran and contrast WSDI has a significant increasing slope in Iran. The trend slope was also calculated using the Theil-Sen estimate test for each season. For example, in the autumn season (SON), the CSDI index in the historical period (1965-2005) shows a decreasing trend of 1.38 days/decade. In contrast, the WSDI index increased by 0.48 days /decade in the same season. The largest increase in the WSDI index is related to the summer season (JJA) under the RCP8.5 scenario, which will increase by 8.77 days/decade (Fig. 9).

\section{Conclusion}

In this study, we examined the mean of daily minimum temperature (TN) and mean of daily maximum temperature (TX) of five models including HadGEM2-ES, IPSL-CM5A-LR, MIROC-ESM-CHEM, GFDLESM2M, and NorESM1-M from the set of CMIP5 Bias-Correction models on a seasonal scale.

Our results showed that GFDL-ESM2M and HadGEM2-ES models have the highest and NorESM1-M and IPSL-CM5A-LR models have the lowest performances in simulating temperature in Iran. We put these five models together with the independence weighted mean (IWM) method and we showed that multi-model ensembles (MME) in the country-wide average has a higher performance than individual CMIP5 models in all seasons.

The results of this study in applying CMIP5 models for TN and TX on the one hand and investigating seasonal ETI in Iran on the other hand have two major advantages over previous studies in Iran. 1- Most studies of CMIP5 models in Iran have used the uncorrected biased output of these models (Zamani \& Berndtsson, 2019; Abbasian et al. 2019; Rahimi et al. 2020; Zamani et al. 2020; Naderi, 2020; Kamyar et al. 2020) and 2 - Few studies that have examined climate extreme of Iran with CMIP models rely on the output of individual models that has definitely with high uncertainty (Roshan \& Nastos, 2018; Katiraie Boroujerdy et al. 2019; Darand, 2020; Sharafati \& Pezeshki, 2020).

The results showed that the frequency and duration of the CSDI period under RCP4.5 and RCP8.5 scenarios decrease in Iran. In contrast, the duration of warm spells increases, which may significantly increase the health risks of heatwaves in Iran. Globally, increasing the frequency of high-temperature 
extremes and decreasing the frequency of low-temperature extremes has also been approved by Min et al. (2013). The results of the present study also confirm it. At the end of the present century, under the RCP8.5 scenario, the WSDI index has shown a 62.6 day increase in summer, while the CSDI is decreasing by a maximum of 3.43 days compared to the historical period.

Significant reduction of cold spells may negatively affect the health of Iranian society and natural ecosystems. In this regard, Diffenbaugh et al. (2008) showed that lowering the minimum temperature increases the growth of pests.

The WSDI will significantly increase in Iran under RCP4.5 and RCP8.5 scenarios. The WSDI anomalies increase on the coasts of the Persian Gulf and the coasts of the Sea of Oman by the end of the century under the RCP8.5 scenario. The WSDI anomalies include 72.9 days in autumn, 64.6 days in winter, 59.8 days in spring, and 80.3 days in summer compared to the historical period (1965-2005).

Global warming has not only increased the minimum (TN) and maximum (TX) temperature in Iran; it also increases the consecutive periods of high-temperature extreme events (for example, WSDI and CSU). The minimum temperature will increase from $0.43^{\circ}$ to $7.60^{\circ}$ and the maximum temperature will increase from $1.66^{\circ}$ to $6.11^{\circ}$ across Iran on a seasonal scale.

In this regard, Zwiers et al. (2011) confirmed the increase in global minimum and maximum temperatures. Almost no cold spell can be detected in Iran under the RCP8.5 scenario in the far future (2061-2100). Significant decrease in the CSDI and increase in the WSDI is not only seen in Iran but also in some areas such as China (Chen \& Zhang, 2016), nine major basins in China (Xu et al. 2019), and even globally (Lu et al. 2018) these extensive changes is also reported using CMIP5 models and more recently with CMIP6 models (Kim et al. 2020).

The CFD and CSU indices, which depicted the highest consecutive days of frost and summer days in Iran showed that the CFD (CSU) will decrease (increase) in the future under the scenarios of RCP4.5 and RCP8.5. The highest decrease of CFD is in winter (DJF) by an average of 13.49 days in the period 20612100 under the RCP8.5 scenario. The autumn has the second-highest decrease in CFD in Iran.

The CSU, on the other hand, shows a steep slope rising toward the transition seasons (spring and autumn). The maximum consecutive summer days are in autumn with 20.51 days and then in spring with 18.79 days. Our results show that summer days are increasing and the length of spring and autumn seasons will be shorter at the end of this century. In contrast, the summer season in Iran will expand by the end of the century. The frequency of summer days will increase by $42.25 \%$ in Iran under the RCP8.5 scenario.

In general, it seems that under the conditions of future climate change, planning should be subject to taking into account the above conditions, including a decrease in the number of frosty days and a significant increase in summer days. The results of this study are of great importance in the planning of energy systems, agriculture, and water resources management. 


\section{Declarations}

\section{Acknowledgment}

This research was funded by the Vice Chancellor for Research of Ferdowsi University of Mashhad, which is hereby acknowledged. We would like to thank the Iran Meteorological Organization (IRIMO) for providing the necessary data and information. We also acknowledge the Inter-Sectoral Impact Model Intercomparison Project (ISIMIP) and associated World Climate Research Program (WCRP) for the production of the data.

Conflict of interest: The authors declare that they have no conflict of interest.

Funding: Vice Chancellor for Research of Ferdowsi University of Mashhad

\section{Authors' contributions}

Conceived and designed the analysis: Azar Zarrin and Abbasali Dadashi-Roudbari

Collected the data: Azar Zarrin, Abbasali Dadashi-Roudbari, and Samira Hassani

Contributed data or analysis tools: Azar Zarrin, Abbasali Dadashi-Roudbari, and Samira Hassani

Performed the analysis: Azar Zarrin and Abbasali Dadashi-Roudbari

Wrote the paper: Azar Zarrin and Abbasali Dadashi-Roudbari

Writing-review, and editing: Azar Zarrin

\section{Availability of data and material}

Daily minimum and maximum temperature are provided by the Inter-Sectoral Impact Model Intercomparison Project (ISIMIP) (https://esg.pik-potsdam.de/search/isimip/).

\section{Code availability}

The $\mathrm{R}$ package used in this paper is available on github (https://github.com/ECCC-CDAS/RClimDex)

\section{Ethics approval}

We approve the ethical responsibilities of authors.

\section{Consent to participate}

Not applicable

Consent for publication 


\section{References}

1. Abbasian M, Moghim S, Abrishamchi A (2019) Performance of the general circulation models in simulating temperature and precipitation over Iran. Theoret Appl Climatol 135(3-4):1465-1483

2. Ahmed K, Sachindra DA, Shahid S, Iqbal Z, Nawaz N, Khan N (2020) Multi-model ensemble predictions of precipitation and temperature using machine learning algorithms. Atmos Res 236:104806

3. Alexander LV, Arblaster JM (2017) Historical and projected trends in temperature and precipitation extremes in Australia in observations and CMIP5. Weather Climate Extremes 15:34-56

4. Alexander LV, Zhang X, Peterson TC, Caesar J, Gleason B, Klein Tank AMG, ... Tagipour A (2006) Global observed changes in daily climate extremes of temperature and precipitation. Journal of Geophysical Research: Atmospheres 111:D5

5. Ali S, Eum HI, Cho J, Dan L, Khan F, Dairaku K, ... Fahad S (2019) Assessment of climate extremes in future projections downscaled by multiple statistical downscaling methods over Pakistan. Atmos Res 222:114-133

6. Anandhi A, Hutchinson S, Harrington J, Rahmani V, Kirkham MB, Rice CW (2016) Changes in spatial and temporal trends in wet, dry, warm and cold spell length or duration indices in Kansas, USA. Int J Climatol 36(12):4085-4101

7. Añel JA, Fernández-González M, Labandeira X, López-Otero X, De la Torre L (2017) Impact of cold waves and heat waves on the energy production sector. Atmosphere 8(11):209

8. Azarderakhsh M, Prakash S, Zhao Y, AghaKouchak A (2020) Satellite-Based Analysis of Extreme Land Surface Temperatures and Diurnal Variability Across the Hottest Place on Earth. IEEE Geoscience and Remote Sensing Letters

9. Bai H, Xiao D, Wang B, Liu DL, Feng P, Tang J (2020) Multi-model ensemble of CMIP6 projections for future extreme climate stress on wheat in the North China Plain. International Journal of Climatology

10. Barnett AG, Hajat S, Gasparrini A, Rocklöv J (2012) Cold and heat waves in the United States. Environmental research 112:218-224

11. Bishop CH, Abramowitz G (2013) Climate model dependence and the replicate Earth paradigm. Climate dynamics 41(3-4):885-900

12. Boucher $O$ (2018) The Geoengineering Model Intercomparison Project-introduction to the second special issue

13. Bozkurt D, Rojas M, Boisier JP, Rondanelli R, Garreaud R, Gallardo L (2019) Dynamical downscaling over the complex terrain of southwest South America: present climate conditions and added value analysis. Clim Dyn 53(11):6745-6767

14. Calton B, Schellekens J, Torre M-DL, A (2016) Water resource reanalysis v1: Data access and model verification results. Earth System Science Data, 36(23) 
15. Carvalho D, Rocha A, Gómez-Gesteira M, Santos CS (2017) Potential impacts of climate change on European wind energy resource under the CMIP5 future climate projections. Renewable Energy 101:29-40

16. Chen YD, Li J, Zhang Q (2016) Changes in site-scale temperature extremes over China during 20712100 in CMIP5 simulations. Journal of Geophysical Research: Atmospheres 121(6):2732-2749

17. Collins WJ, Bellouin N, Doutriaux-Boucher M, Gedney N, Hinton T, Jones CD, ... Senior C (2008) Evaluation of the HadGEM2 model. Hadley Centre Technical Note HCTN 74, Met Office Hadley Centre, Exeter, UK

18. Cook J, Nuccitelli D, Green SA, Richardson M, Winkler B, Painting R, ... Skuce A (2013) Quantifying the consensus on anthropogenic global warming in the scientific literature. Environmental research letters 8(2):024024

19. Darand M (2020) Future changes in temperature extremes in climate variability over I ran. Meteorological Applications, 27(6), e1968

20. Darand M, Masoodian A, Nazaripour H, Daneshvar MM (2015) Spatial and temporal trend analysis of temperature extremes based on Iranian climatic database (1962-2004). Arab J Geosci 8(10):8469-8480

21. Donat MG, Alexander LV, Herold N, Dittus AJ (2016) Temperature and precipitation extremes in century-long gridded observations, reanalyses, and atmospheric model simulations. Journal of Geophysical Research: Atmospheres 121(19):11-174

22. Donat MG, Alexander LV, Yang H, Durre I, Vose R, Dunn RJH, ... Hewitson B (2013) Updated analyses of temperature and precipitation extreme indices since the beginning of the twentieth century: The HadEX2 dataset. Journal of Geophysical Research: Atmospheres 118(5):2098-2118

23. Dong S, Xu Y, Zhou B, Shi Y (2015) Assessment of indices of temperature extremes simulated by multiple CMIP5 models over China. Adv Atmos Sci 32(8):1077-1091

24. Dunne JP, John JG, Adcroft AJ, Griffies SM, Hallberg RW, Shevliakova E, ... Krasting JP (2012) GFDL's ESM2 global coupled climate-carbon earth system models. Part I: Physical formulation and baseline simulation characteristics. J Clim 25(19):6646-6665

25. Fallah-Ghalhari G, Shakeri F, Dadashi-Roudbari A (2019) Impacts of climate changes on the maximum and minimum temperature in Iran. Theoret Appl Climatol 138(3-4):1539-1562

26. Field CB, Barros V, Stocker TF, Dahe Q (eds) (2012) Managing the risks of extreme events and disasters to advance climate change adaptation: special report of the intergovernmental panel on climate change. Cambridge University Press

27. Gaitán E, Monjo R, Pórtoles J, Pino-Otín MR (2019) Projection of temperatures and heat and cold waves for Aragón (Spain) using a two-step statistical downscaling of CMIP5 model outputs. Science of The Total Environment 650:2778-2795

28. Gao J, Sheshukov AY, Yen H, Douglas-Mankin KR, White MJ, Arnold JG (2019) Uncertainty of hydrologic processes caused by bias-corrected CMIP5 climate change projections with alternative historical data sources. J Hydrol 568:551-561 
29. Heavens NG, Mahowald NM, Soreghan GS, Soreghan MJ, Shields CA (2015) A model-based evaluation of tropical climate in Pangaea during the late Palaeozoic icehouse. Palaeogeogr Palaeoclimatol Palaeoecol 425:109-127

30. Hong YIN, Ying SUN (2018) Characteristics of extreme temperature and precipitation in China in 2017 based on ETCCDI indices. Advances in Climate Change Research 9(4):218-226

31. Im ES, Pal JS, Eltahir EA (2017) Deadly heat waves projected in the densely populated agricultural regions of South Asia. Sci Adv 3(8):e1603322

32. IPCC (2013) In: Stocker TF, Qin D, Plattner G-K, Tignor M, Allen SK, Boschung J, Nauels A, Xia Y, Bex V, Midgley PM (eds), Climate Change 2013: The Physical Science Basis. Contribution of Working Group I to the Fifth Assessment Report of the Intergovernmental Panelon Climate Change. Cambridge University Press, Cambridge https://doi.org/10.1017/СВ09781107415324

33. Iversen T, Bentsen M, Bethke I, Debernard JB, Kirkevåg A, Seland Ø, ... Seierstad IA (2013) The Norwegian earth system model, NorESM1-M-part 2: Climate response and scenario projections. Geosci Model Dev 6(2):389

34. Ju H, van der Velde M, Lin E, Xiong W, Li Y (2013) The impacts of climate change on agricultural production systems in China. Clim Change 120(1-2):313-324

35. Kamyar A, Yazdanpanah H, Movahedi S, Morimoto D (2020) Assessment of the impacts of climate change on agro-climatic indices in Iran. Theoret Appl Climatol 142(3):1359-1367

36. Katiraie-Boroujerdy PS, Asanjan A, Chavoshian A, Hsu A, K. L., \& Sorooshian S (2019) Assessment of seven CMIP5 model precipitation extremes over Iran based on a satellite-based climate data set. Int $\mathrm{J}$ Climatol 39(8):3505-3522

37. Kent ST, McClure LA, Zaitchik BF, Smith TT, Gohlke JM (2014) Heat waves and health outcomes in Alabama (USA): the importance of heat wave definition. Environmental health perspectives 122(2):151-158

38. Kharin VV, Zwiers FW, Zhang X, Wehner M (2013) Changes in temperature and precipitation extremes in the CMIP5 ensemble. Climatic change 119(2):345-357

39. Kim YH, Min SK, Zhang X, Sillmann J, Sandstad M (2020) Evaluation of the CMIP6 multi-model ensemble for climate extreme indices. Weather Climate Extremes 29:100269

40. Knutti R, Sedláček J (2013) Robustness and uncertainties in the new CMIP5 climate model projections. Nature Climate Change 3(4):369-373

41. Kouzegaran S, Baygi MM, Babaeian I, Khashei-Siuki A (2020) Modeling of the saffron yield in Central Khorasan region based on meteorological extreme events. Theoret Appl Climatol 139(3):1207-1217

42. Kumar D, Kodra E, Ganguly AR (2014) Regional and seasonal intercomparison of CMIP3 and CMIP5 climate model ensembles for temperature and precipitation. Climate dynamics 43(9-10):2491-2518

43. Lange S (2018) Bias correction of surface downwelling longwave and shortwave radiation for the EWEMBI dataset 
44. Lu C, Sun Y, Zhang X (2018) Multimodel detection and attribution of changes in warm and cold spell durations. Environmental Research Letters 13(7):074013

45. LUO N, GUO Y, GAO Z, CHEN K, CHOU J (2020) Assessment of CMIP6 and CMIP5 model performance for extreme temperature in China. Atmospheric Oceanic Science Letters 13(6):589-597

46. Manzanas R, Gutiérrez JM, Fernández J, Van Meijgaard E, Calmanti S, Magariño ME, ... Herrera S (2018) Dynamical and statistical downscaling of seasonal temperature forecasts in Europe: Added value for user applications. Climate Services 9:44-56

47. Merlone A, Al-Dashti H, Faisal N, Cerveny RS, AlSarmi S, Bessemoulin P, ... Rahimzadeh F (2019) Temperature extreme records: World Meteorological Organization metrological and meteorological evaluation of the 54.0 C observations in Mitribah, Kuwait and Turbat, Pakistan in 2016/2017. Int J Climatol 39(13):5154-5169

48. Min SK, Zhang X, Zwiers F, Shiogama H, Tung YS, Wehner M (2013) Multimodel detection and attribution of extreme temperature changes. J Clim 26(19):7430-7451

49. Moss RH, Edmonds JA, Hibbard KA, Manning MR, Rose SK, Van Vuuren DP, ... Meehl GA (2010) The next generation of scenarios for climate change research and assessment. Nature 463(7282):747756

50. Mushore TD, Mutanga O, Odindi J, Dube T (2018) Determining extreme heat vulnerability of Harare Metropolitan City using multispectral remote sensing and socio-economic data. Journal of Spatial Science 63(1):173-191

51. Naderi M (2020) Extreme climate events under global warming in northern Fars Province, southern Iran. Theoret Appl Climatol 142(3):1221-1243

52. Navarro-Racines C, Tarapues J, Thornton P, Jarvis A, Ramirez-Villegas J (2020) High-resolution and bias-corrected CMIP5 projections for climate change impact assessments. Scientific Data 7(1):1-14

53. Noor M, bin Ismail T, Shahid S, Ahmed K, Chung ES, Nawaz N (2019) Selection of CMIP5 multi-model ensemble for the projection of spatial and temporal variability of rainfall in peninsular Malaysia. Theoret Appl Climatol 138(1-2):999-1012

54. Ntoumos A, Hadjinicolaou P, Zittis G, Lelieveld J (2020) Updated Assessment of Temperature Extremes over the Middle East-North Africa (MENA) Region from Observational and CMIP5 Data. Atmosphere 11(8):813

55. Ongoma V, Chen H, Gao C, Nyongesa AM, Polong F (2018) Future changes in climate extremes over Equatorial East Africa based on CMIP5 multimodel ensemble. Nat Hazards 90(2):901-920

56. Pepin N, Bradley RS, Diaz HF, Baraër M, Caceres EB, Forsythe N, ... Miller JR (2015) Elevationdependent warming in mountain regions of the world. Nature climate change 5(5):424-430

57. Peterson TC, Heim RR Jr, Hirsch R, Kaiser DP, Brooks H, Diffenbaugh NS, ... Katz RW (2013) Monitoring and understanding changes in heat waves, cold waves, floods, and droughts in the United States: state of knowledge. Bull Am Meteor Soc 94(6):821-834

58. Piticar A, Croitoru AE, Ciupertea FA, Harpa GV (2018) Recent changes in heat waves and cold waves detected based on excess heat factor and excess cold factor in Romania. Int J Climatol 38(4):1777- 
1793

59. Rahimi J, Laux P, Khalili A (2020) Assessment of climate change over Iran: CMIP5 results and their presentation in terms of Köppen-Geiger climate zones. Theoretical and Applied Climatology, 1-17

60. Rahimi M, Hejabi S (2018) Spatial and temporal analysis of trends in extreme temperature indices in Iran over the period 1960-2014. Int J Climatol 38(1):272-282

61. Rahimzadeh F, Asgari A, Fattahi E (2009) Variability of extreme temperature and precipitation in Iran during recent decades. International Journal of Climatology: A Journal of the Royal Meteorological Society 29(3):329-343

62. Reyers M, Moemken J, Pinto JG (2016) Future changes of wind energy potentials over Europe in a large CMIP5 multi-model ensemble. Int J Climatol 36(2):783-796

63. Roshan G, Nastos PT (2018) Assessment of extreme heat stress probabilities in Iran's urban settlements, using first order Markov chain model. Sustainable cities society 36:302-310

64. Schär C (2016) Climate extremes: The worst heat waves to come. Nature Climate Change 6(2):128129

65. Schoof JT, Pryor SC, Ford TW (2019) Projected changes in United States regional extreme heat days derived from bivariate quantile mapping of CMIP5 simulations. Journal of Geophysical Research: Atmospheres 124(10):5214-5232

66. Sharafati A, Pezeshki E (2020) A strategy to assess the uncertainty of a climate change impact on extreme hydrological events in the semi-arid Dehbar catchment in Iran. Theoret Appl Climatol 139(12):389-402

67. Sheridan SC, Lee CC, Smith ET (2020) A comparison between station observations and reanalysis data in the identification of extreme temperature events. Geophysical Research Letters, 47(15), e2020GL088120

68. Sillmann J, Kharin VV, Zwiers FW, Zhang X, Bronaugh D (2013) Climate extremes indices in the CMIP5 multimodel ensemble: Part 2. Future climate projections. Journal of Geophysical Research: Atmospheres 118(6):2473-2493

69. Soltani M, Laux P, Kunstmann H, Stan K, Sohrabi MM, Molanejad M, ... Zawar-Reza P (2016) Assessment of climate variations in temperature and precipitation extreme events over Iran. Theoret Appl Climatol 126(3-4):775-795

70. Suparta W, Yatim ANM (2017, May) An analysis of heat wave trends using heat index in East Malaysia. In Journal of Physics: Conference Series (Vol. 852, No. 1, p. 012005)

71. Taylor KE (2001) Summarizing multiple aspects of model performance in a single diagram. Journal of Geophysical Research: Atmospheres 106(D7):7183-7192

72. Tegegne G, Melesse AM (2020) Multimodel ensemble projection of hydro-climatic extremes for climate change impact assessment on water resources. Water Resour Manage 34(9):3019-3035

73. Tegegne G, Melesse AM, Worqlul AW (2020) Development of multi-model ensemble approach for enhanced assessment of impacts of climate change on climate extremes. Sci Total Environ 
704:135357

74. Ullah S, You Q, Zhang Y, Bhatti AS, Ullah W, Hagan DFT, ... Ali A (2020) Evaluation of CMIP5 models and projected changes in temperatures over South Asia under global warming of $1.5 \mathrm{oC}, 2 \mathrm{oC}$, and 3 oC. Atmos Res 246:105122

75. Vaghefi SA, Keykhai M, Jahanbakhshi F, Sheikholeslami J, Ahmadi A, Yang H, Abbaspour KC (2019) The future of extreme climate in Iran. Scientific reports 9(1):1-11

76. Vuille M, Franquist E, Garreaud R, Casimiro L, W. S., \& Cáceres B (2015) Impact of the global warming hiatus on Andean temperature. Journal of Geophysical Research: Atmospheres 120(9):3745-3757

77. Watanabe S, Hajima T, Sudo K, Nagashima T, Takemura T, Okajima H, ... Ise T (2011) MIROC-ESM 2010: Model description and basic results of CMIP5-20c3m experiments. Geosci Model Dev 4(4):845

78. World Meteorological Organization (2010) No. 1055. 978-92-63-11055-8\$4(Switzerland).

79. Wuebbles D, Goodman A, Janssen E, Lee H, Olsen SC, MeehI G, ... Santer B (2014) CMIP5 climate model analyses: climate extremes in the United States. Bull Am Meteor Soc 95(4):571-583

80. Xu C, Chen Y, Yang Y, Hao X, Shen Y (2010) Hydrology and water resources variation and its response to regional climate change in Xinjiang. J Geog Sci 20(4):599-612

81. Xu K, Wu C, Hu BX (2019) Projected changes of temperature extremes over nine major basins in China based on the CMIP5 multimodel ensembles. Stoch Env Res Risk Assess 33(1):321-339

82. Xu L, Wang A (2019) Application of the bias correction and spatial downscaling algorithm on the temperature extremes from CMIP5 multimodel ensembles in China. Earth Space Science 6(12):2508-2524

83. Yang Y, Tang J, Xiong Z, Wang S, Yuan J (2019) An intercomparison of multiple statistical downscaling methods for daily precipitation and temperature over China: present climate evaluations. Clim Dyn 53(7-8):4629-4649

84. Ying H, Zhang H, Sun Y, Zhao J, Zhang Z, Guo X, ... Deng G (2020) CMIP5-Based Spatiotemporal Changes of Extreme Temperature Events during 2021-2100 in Mainland China. Sustainability 12(11):4418

85. You Q, Jiang Z, Wang D, Pepin N, Kang S (2018) Simulation of temperature extremes in the Tibetan Plateau from CMIP5 models and comparison with gridded observations. Clim Dyn 51(1-2):355-369

86. Yu B, Lin H, Kharin VV, Wang XL (2020) Interannual variability of North American winter temperature extremes and its associated circulation anomalies in observations and CMIP5 simulations. J Clim 33(3):847-865

87. Zamani R, Berndtsson R (2019) Evaluation of CMIP5 models for west and southwest Iran using TOPSIS-based method. Theoret Appl Climatol 137(1-2):533-543

88. Zamani Y, Monfared SAH, Hamidianpour M (2020) A comparison of CMIP6 and CMIP5 projections for precipitation to observational data: the case of Northeastern Iran. Theoret Appl Climatol 142(3):1613-1623 
89. Zarrin A, Dadashi Roudbari A (2020) Projection the Long-Term Outlook Iran Future Temperature Based on the Output of The coupled model intercomparison project phase 6 (CMIP6). Journal of the Earth Space Physics 46(3):583-602. doi:10.22059/jesphys.2020.304870.1007226

90. Zhai J, Mondal SK, Fischer T, Wang Y, Su B, Huang J, ... Uddin MJ (2020) Future drought characteristics through a multi-model ensemble from CMIP6 over South Asia. Atmos Res 246:105111

91. Zhang H, Zhou G, Li Liu D, Wang B, Xiao D, He L (2019) Climate-associated rice yield change in the Northeast China Plain: A simulation analysis based on CMIP5 multi-model ensemble projection. Sci Total Environ 666:126-138

92. Zhang X, Zwiers FW, Hegerl G (2009) The influences of data precision on the calculation of temperature percentile indices. International Journal of Climatology: A Journal of the Royal Meteorological Society 29(3):321-327

93. Zhu J, Huang DQ, Yan PW, Huang Y, Kuang XY (2017) Can reanalysis datasets describe the persistent temperature and precipitation extremes over China? Theoret Appl Climatol 130(1-2):655671

94. Zhu X, Wei Z, Dong W, Ji Z, Wen X, Zheng Z, ... Chen D (2020) Dynamical downscaling simulation and projection for mean and extreme temperature and precipitation over central Asia. Climate Dynamics, pp 1-28

95. Zwiers FW, Zhang X, Feng Y (2011) Anthropogenic influence on long return period daily temperature extremes at regional scales. J Clim 24(3):881-892

\section{Figures}




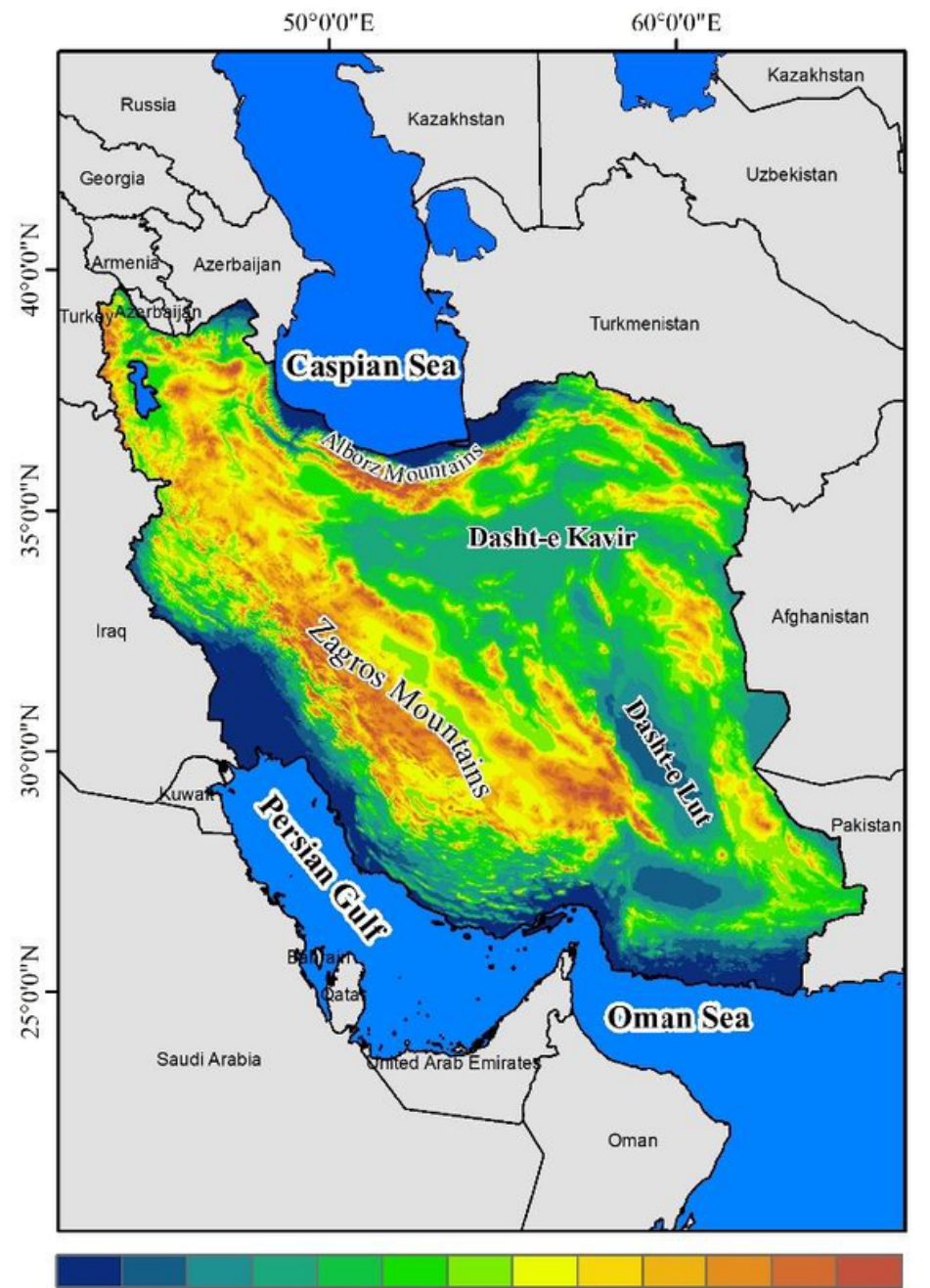

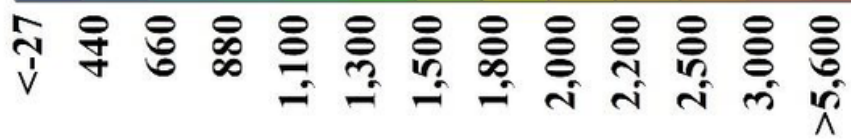

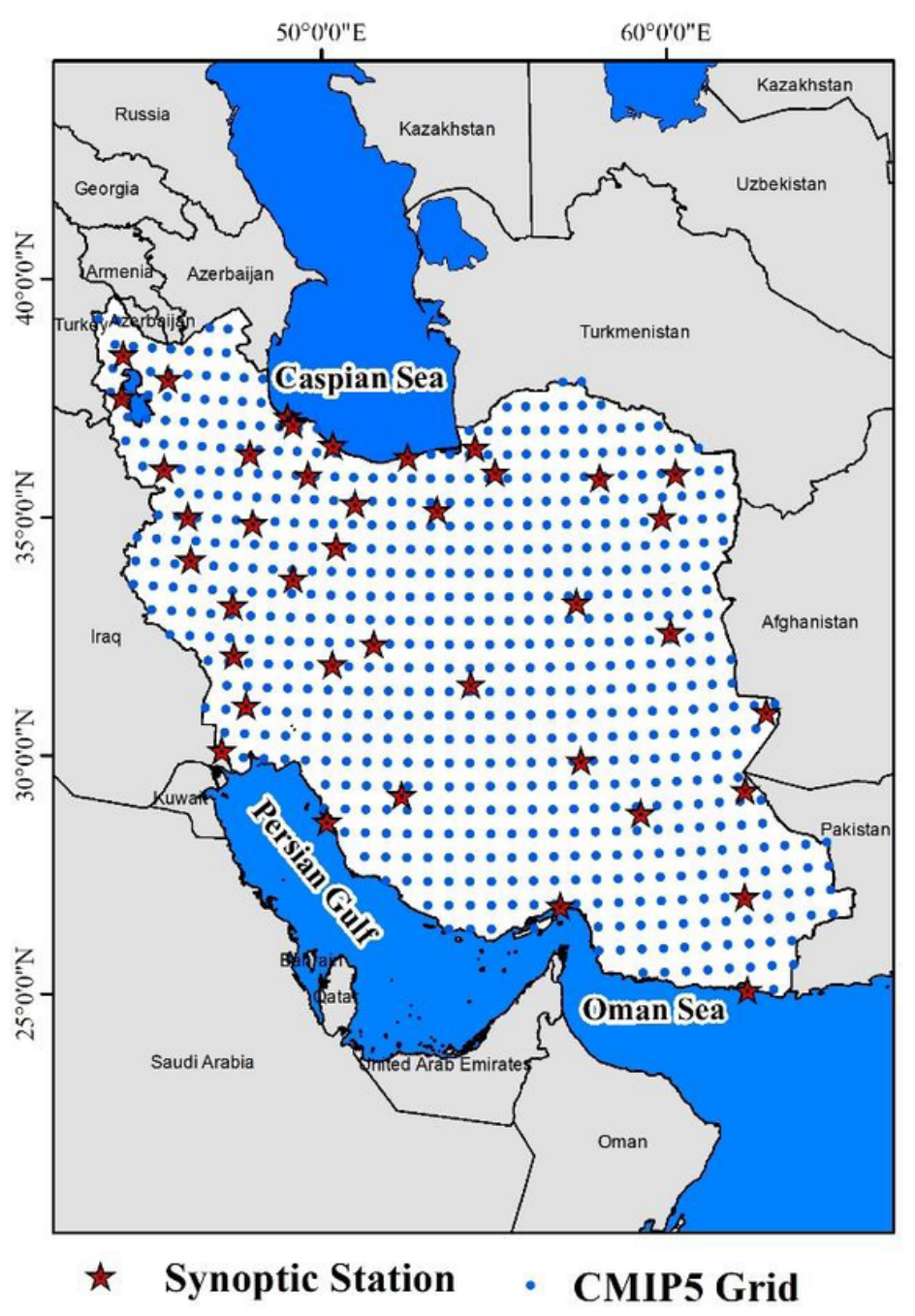

Figure 1

Spatial distribution of synoptic stations over Iran, with Digital Elevation Model (DEM), derived from the SRTM elevation data ( 1 km2) and CMIP5 Grid (0.50). These Synoptic stations provided consistent observations during 1965-2019. 

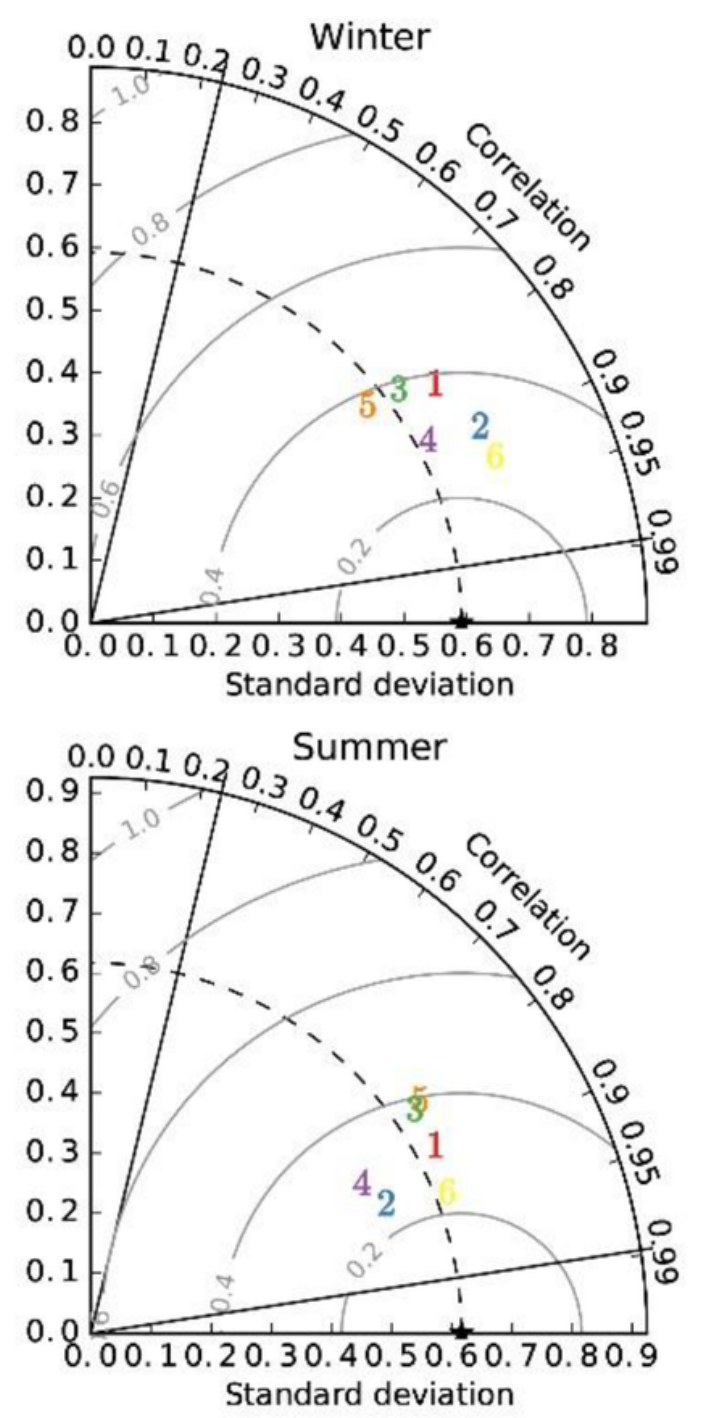

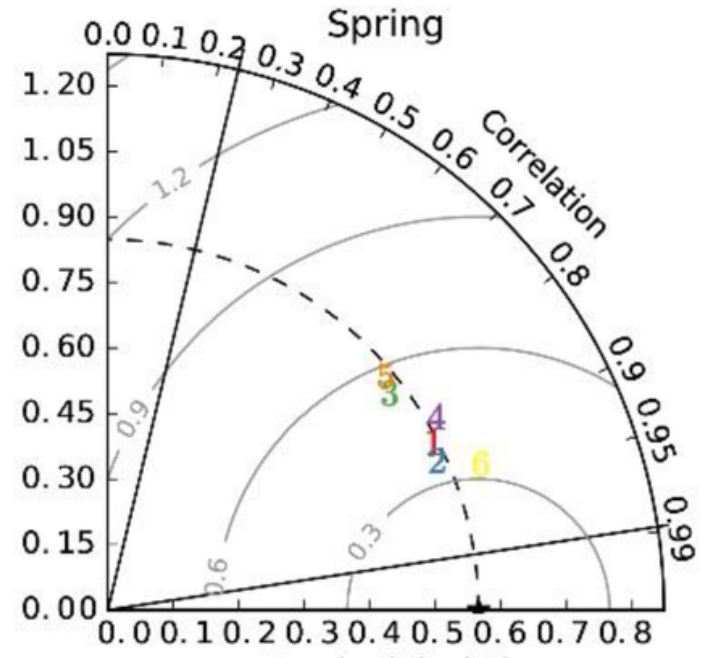

Standard deviation

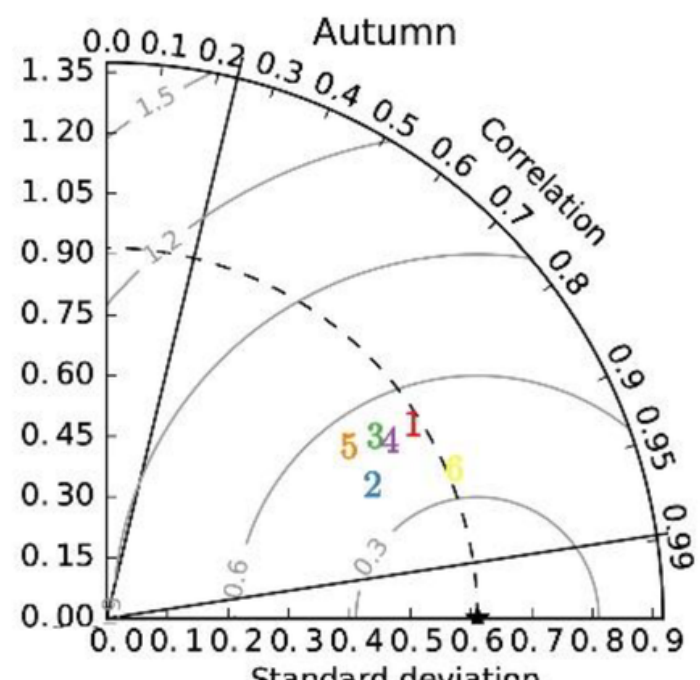

Standard deviation

Figure 2

Validation of CMIP5 Bias-Correction models in Iran using Taylor diagram for minimum temperature 

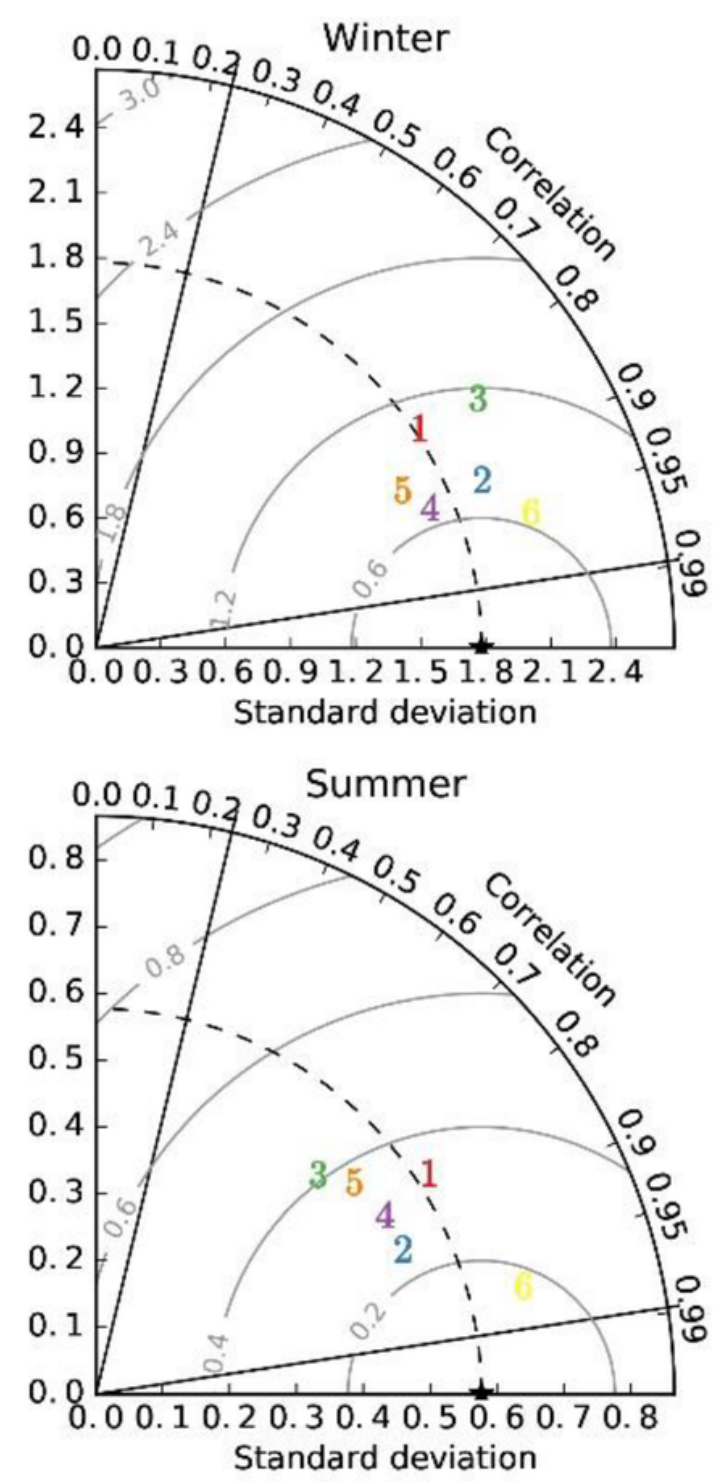

- Reference

1 GFDL-ESM2M

2 HadGEM2-ES

3 IPSL-CM5A-LR

4 MIROC5

5 NorESM1-M

Ensemble
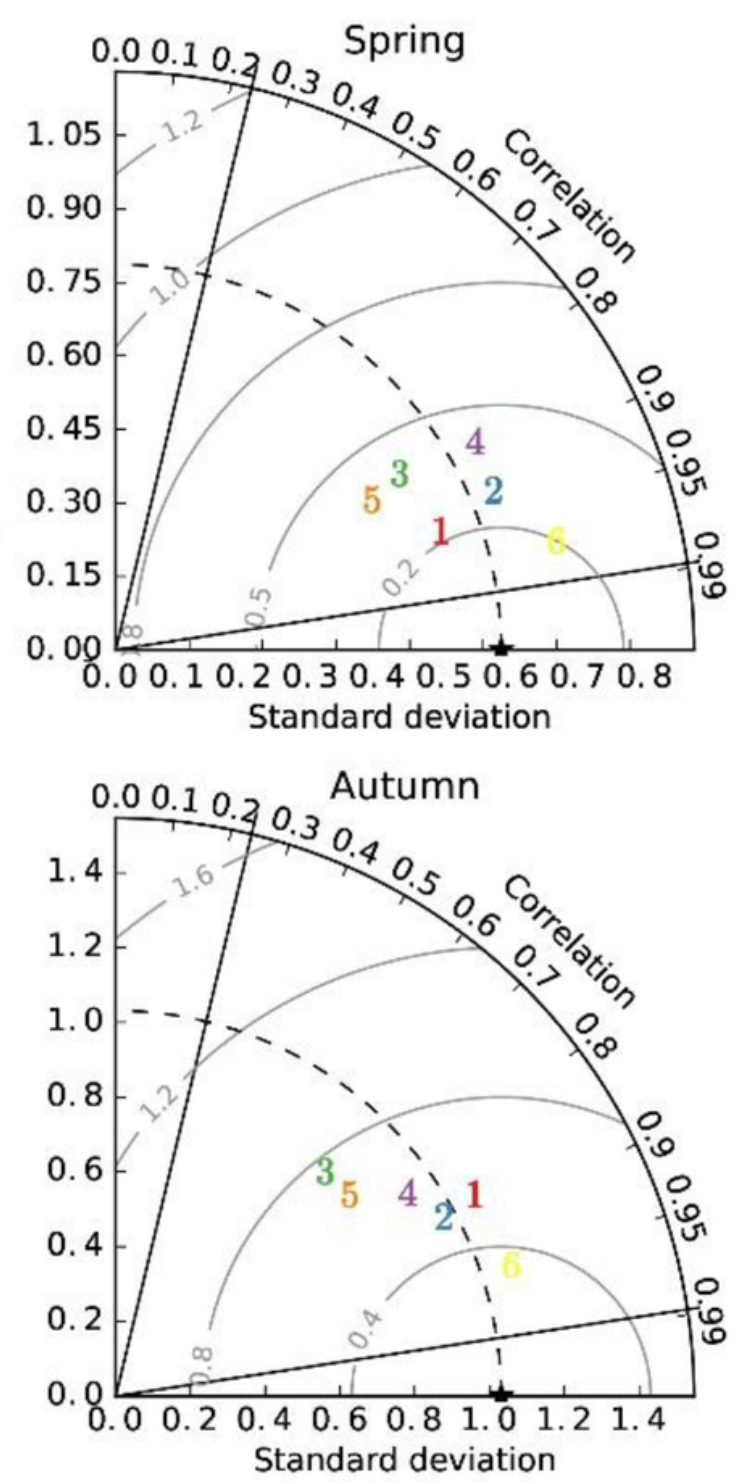

Figure 3

Validation of CMIP5 Bias-Correction models in Iran using Taylor diagram for maximum temperature 


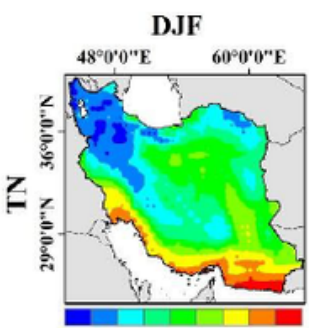

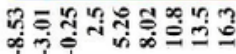

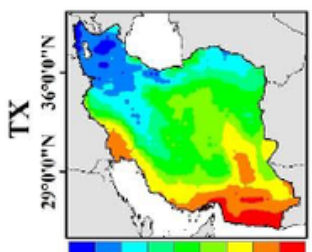

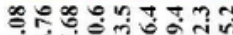
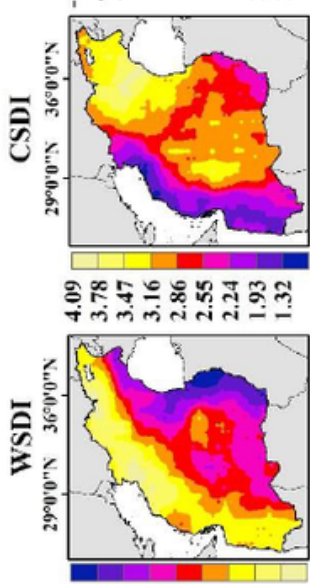

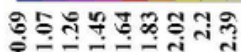

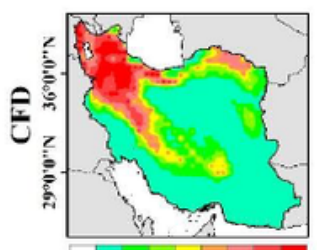

oxor-o in an

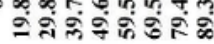

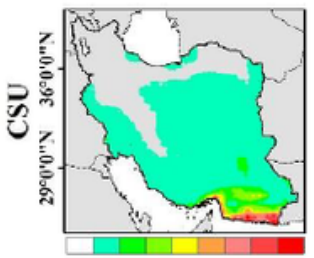

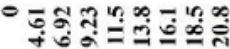

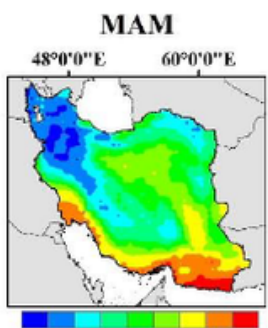

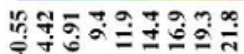

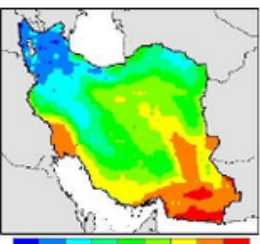

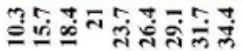

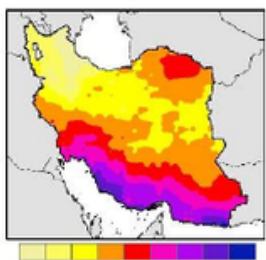

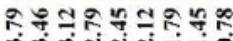

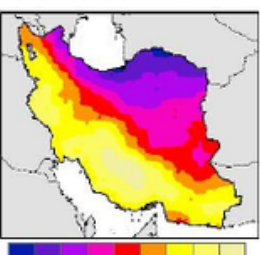

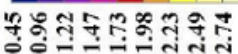

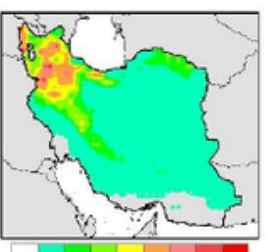

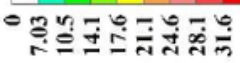

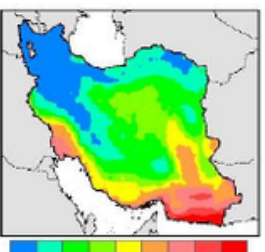

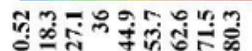

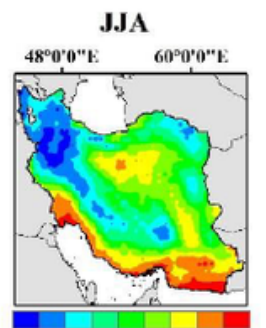

$02-14+0.000$

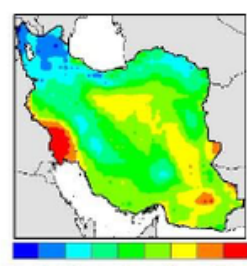

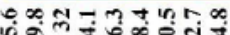

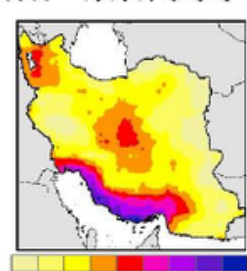

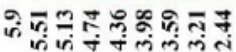

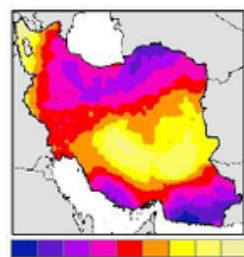

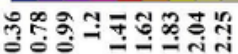

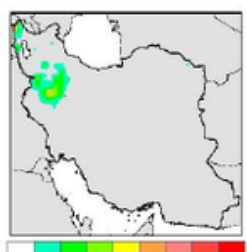

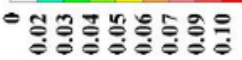

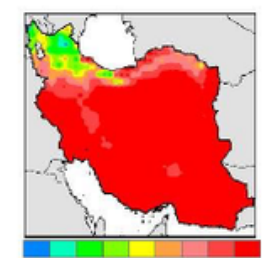

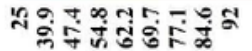

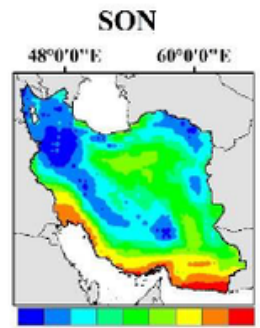

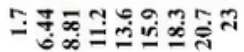

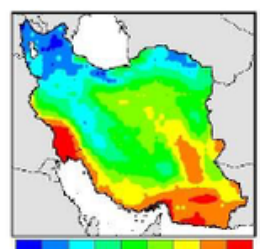

$\Rightarrow 70=000 \%$
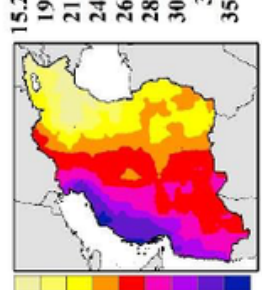

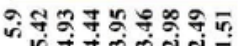

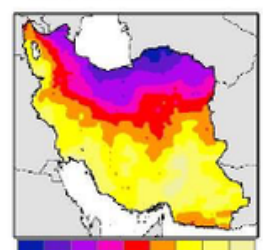

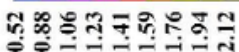
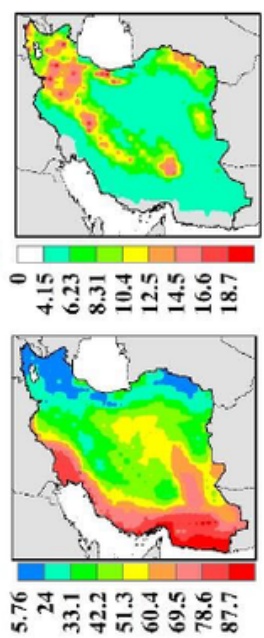

\section{Figure 4}

Long-term seasonal distribution of the ETIS (TN, TX, CSDI, WSDI, CFD, and CSU) during the historical period (1965-2005) in Iran based on CMIP5 output BC MME by IWM method. TN and Tx units: [oC], CSDI, WSDI, CFD, and CSU units: [day] 

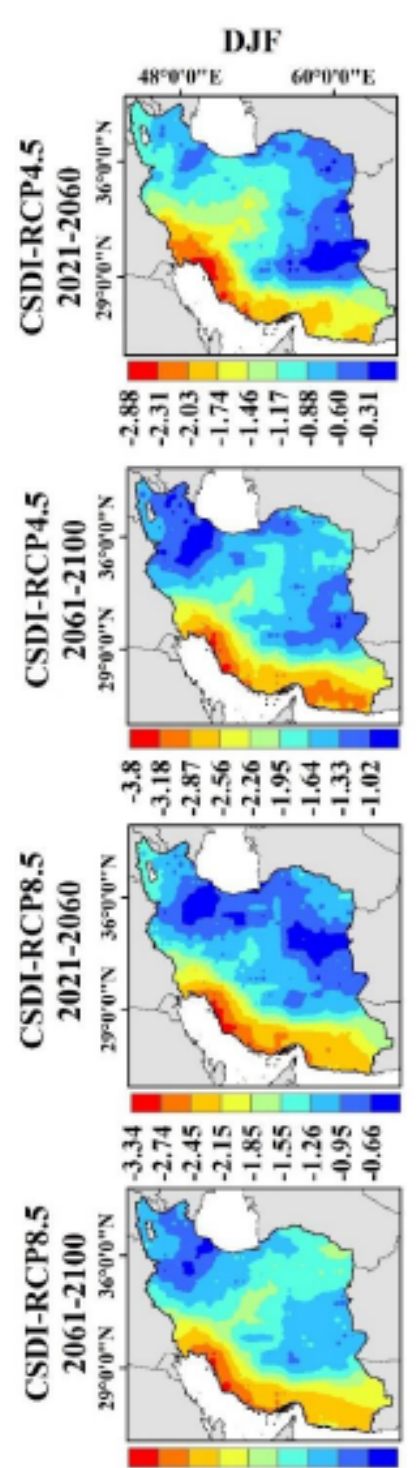

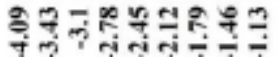

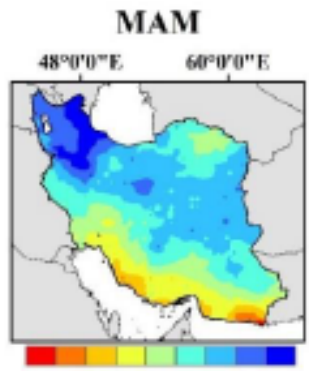

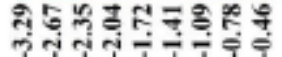

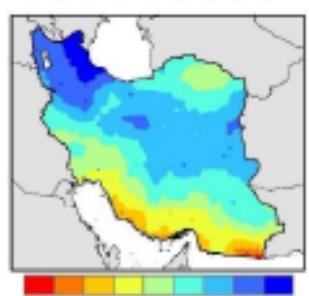

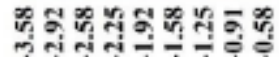

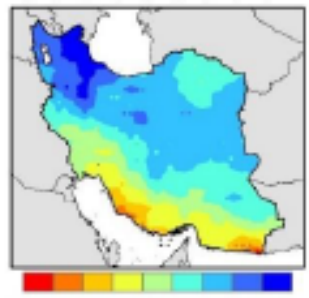

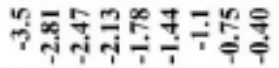

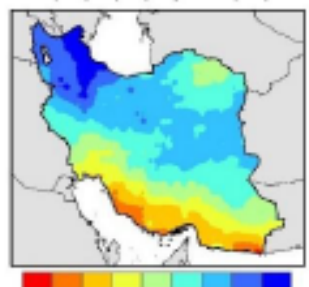

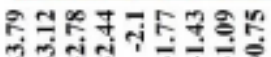

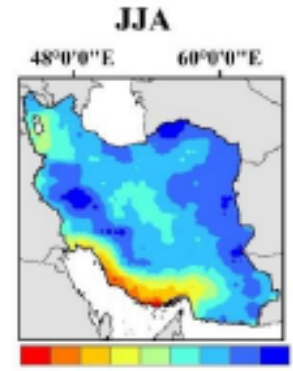

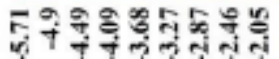

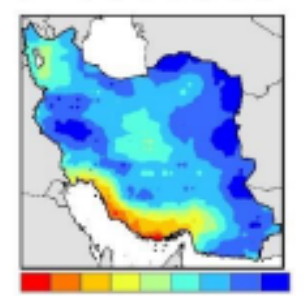

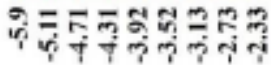

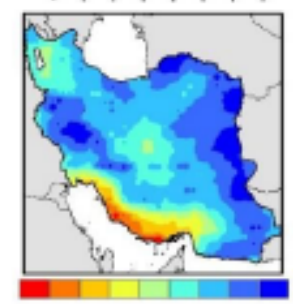

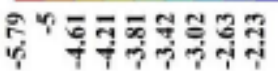

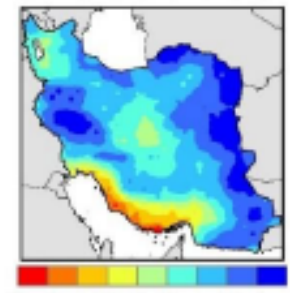

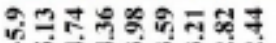

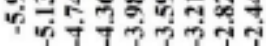

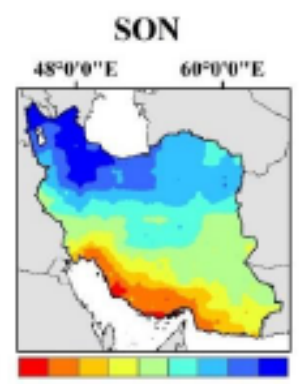

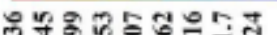

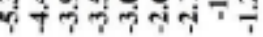

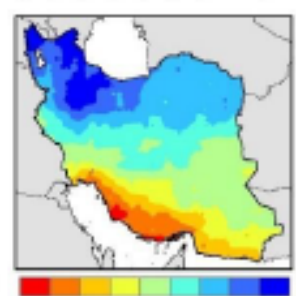

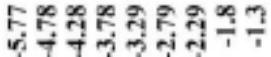

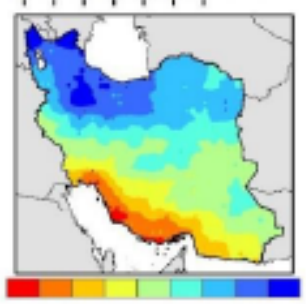

4.

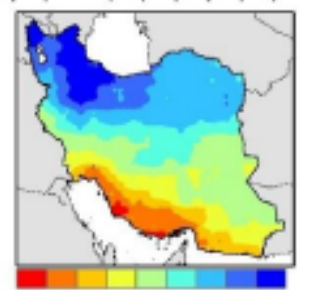

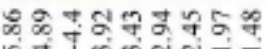

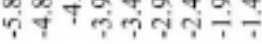

\section{Figure 5}

Seasonal distribution of projected anomalies of CSDI in Iran using ensemble CMIP5 models. the results are based on the output of (RCP4.5) and (RCP8.5) scenarios during the near future (2021-2060) and far future (2061-2100). 


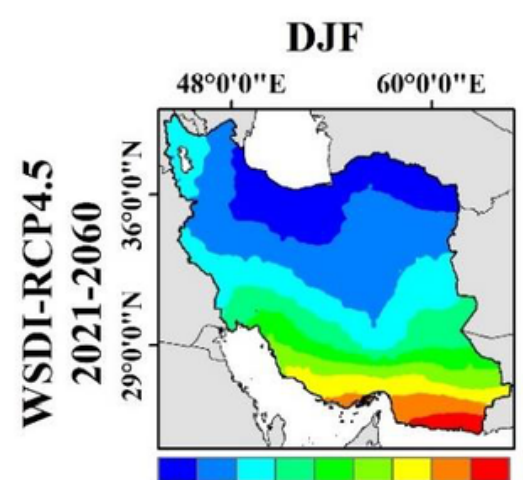

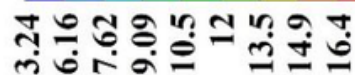

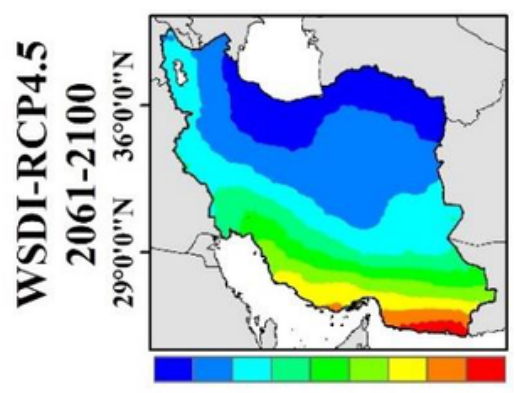

s.ำ

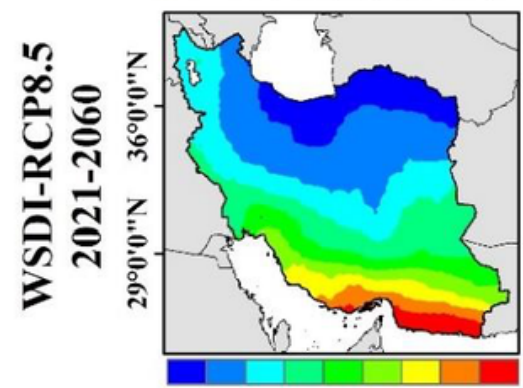

ขึํำ

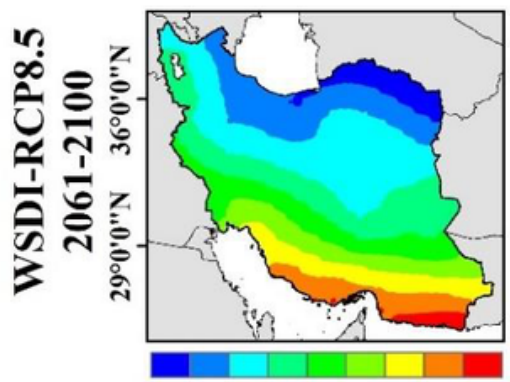

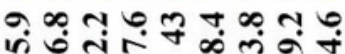

MAM

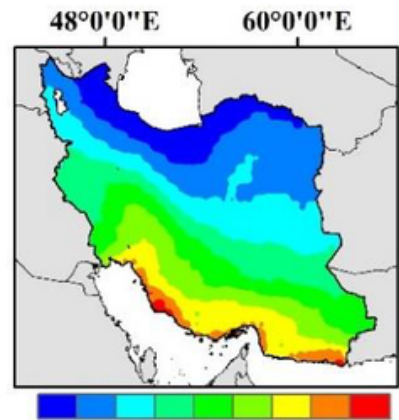

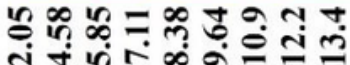

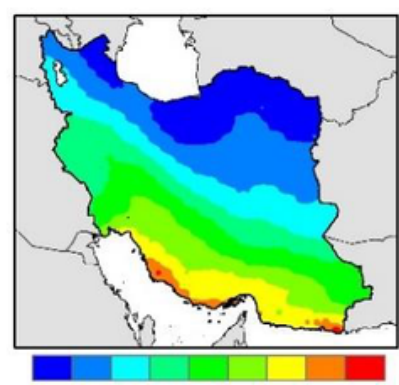

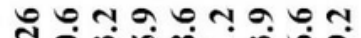

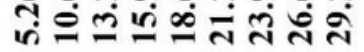

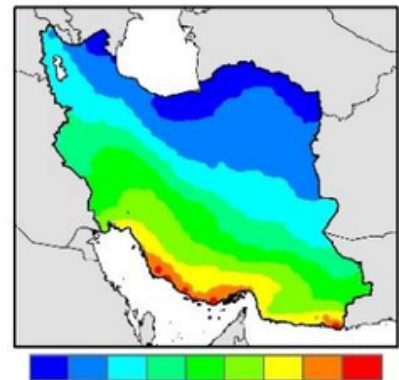

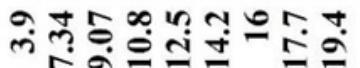

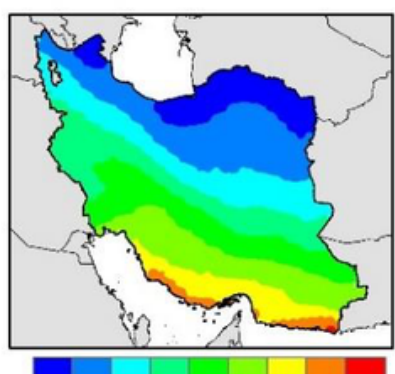

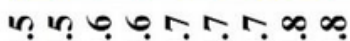
ป तें लें
JJA

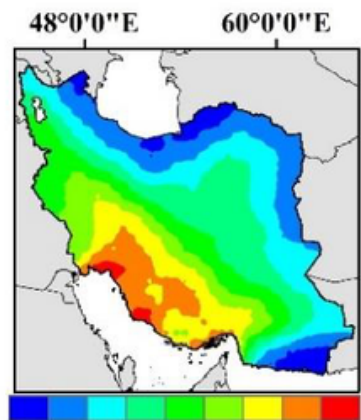

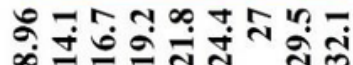

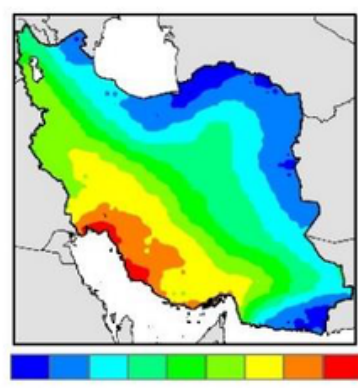

$\infty$ म

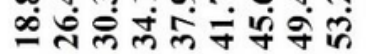

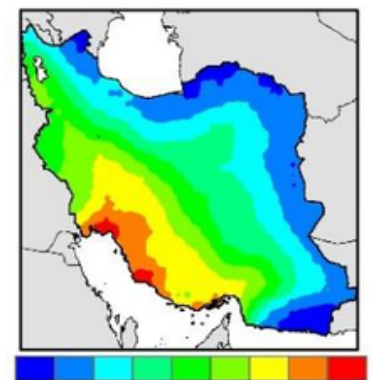

ติำ

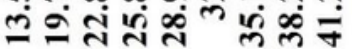

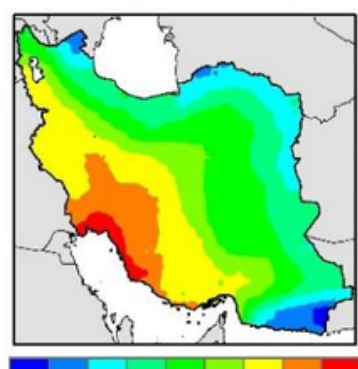

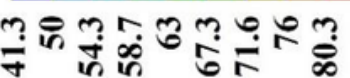

SON

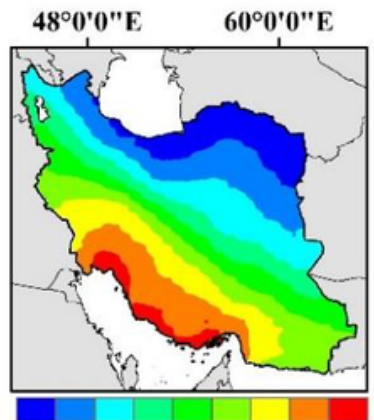

5nogo

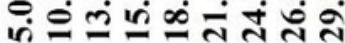

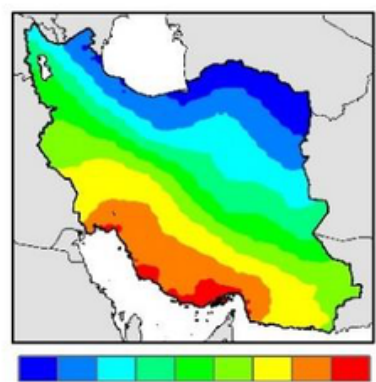

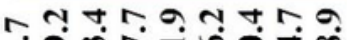

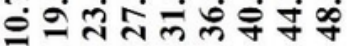

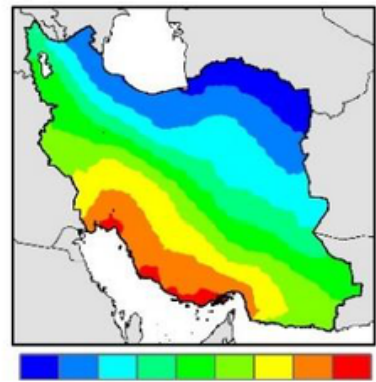

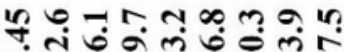

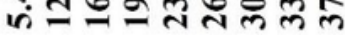

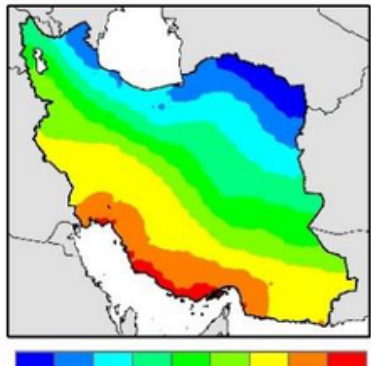

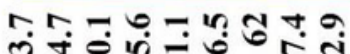

Figure 6

Seasonal distribution of projected anomalies of WSDI in Iran using CMIP5 Bias-Correction models, the ensemble models using IWM method, and the results are based on the output of two (RCP4.5) and (RCP8.5) scenarios during the near future (2060-2021) and far future (2061-2100). 
D.JF

MAM

JJA

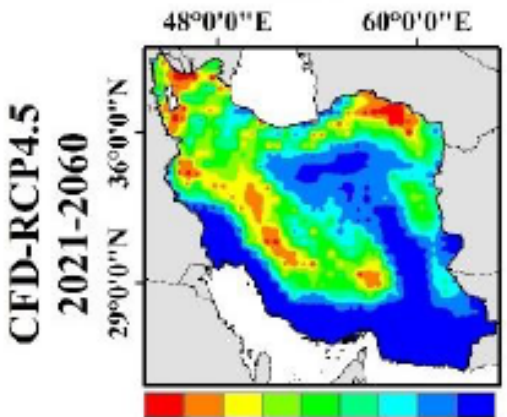

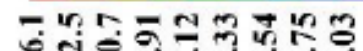

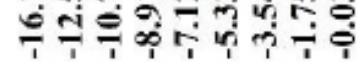

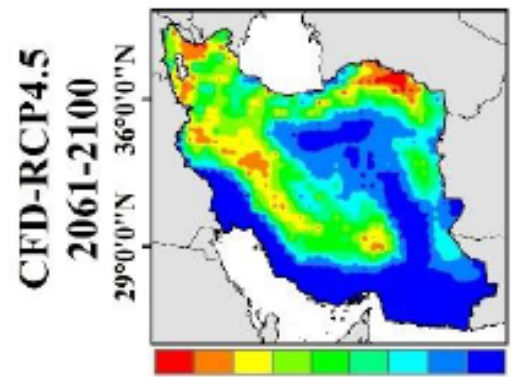

孛음

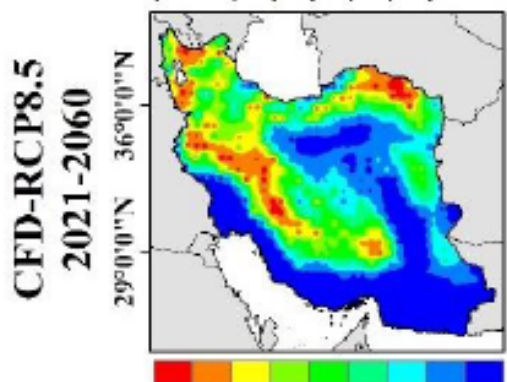

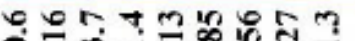

ศิ่

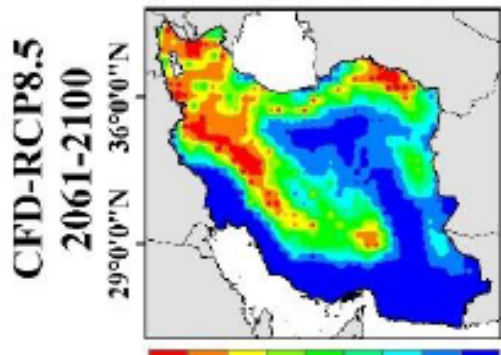

- MTarna

कें

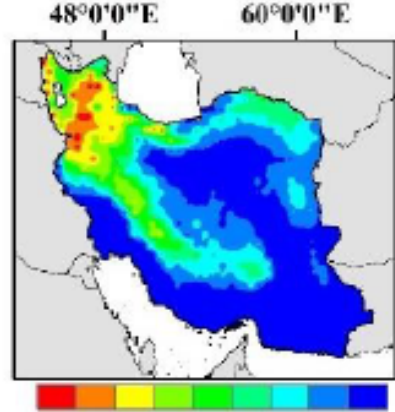

ำ

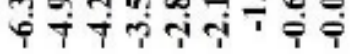

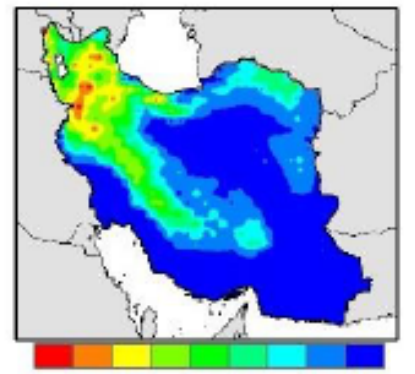

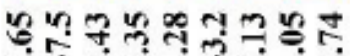
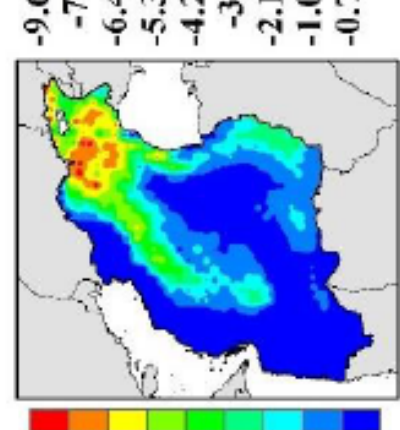

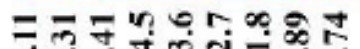
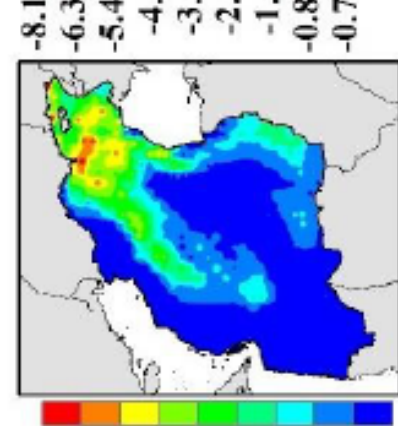

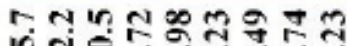

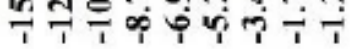

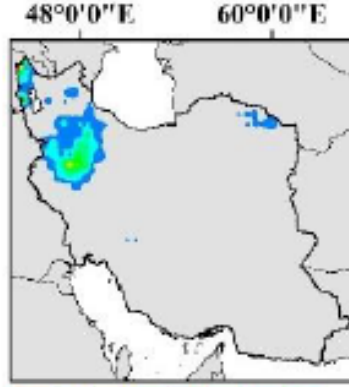

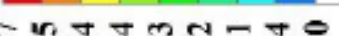

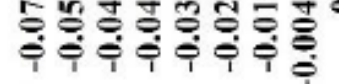

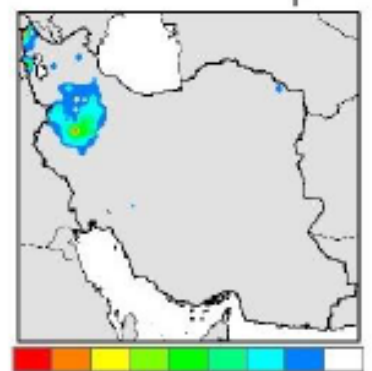

5능

iิ

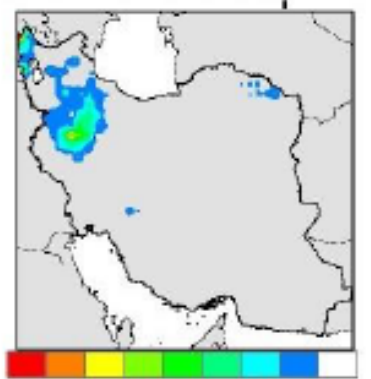

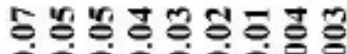
î

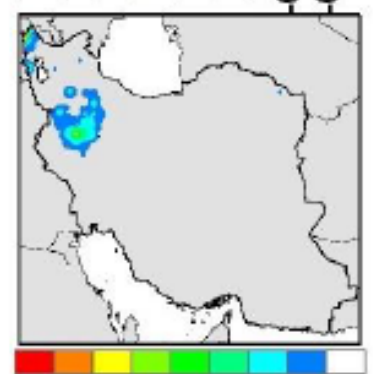

오ำำ

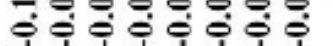

SON

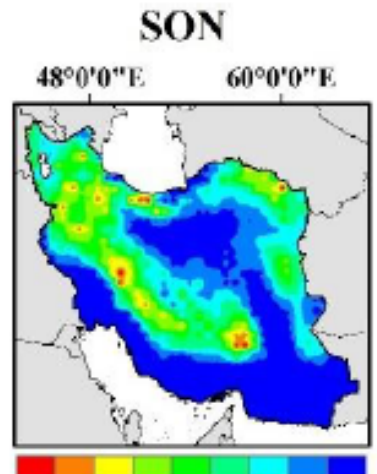

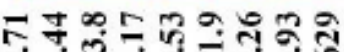

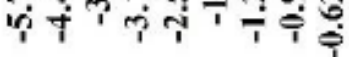

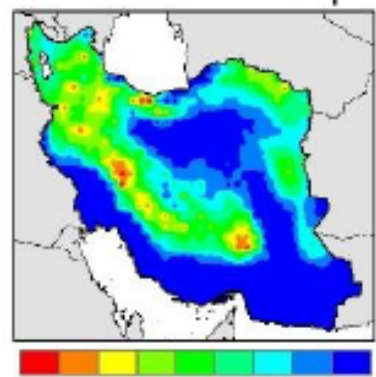

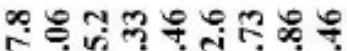

Т़िं

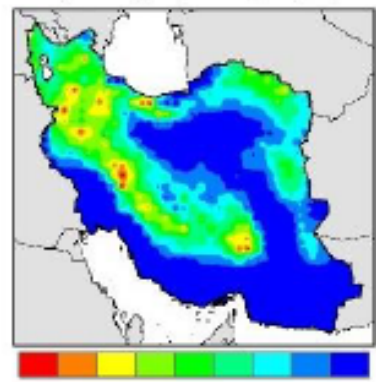

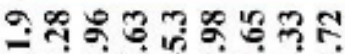

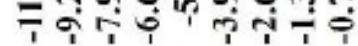

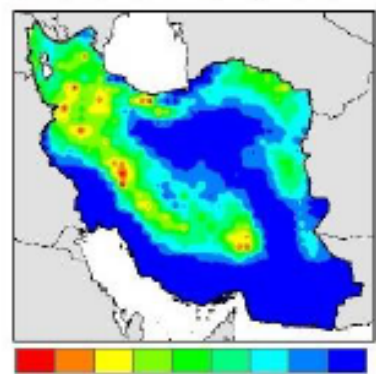

ดุ च

Figure 7

Projection of CFD anomaly in Iran using CMIP5 BC MME 
DJF

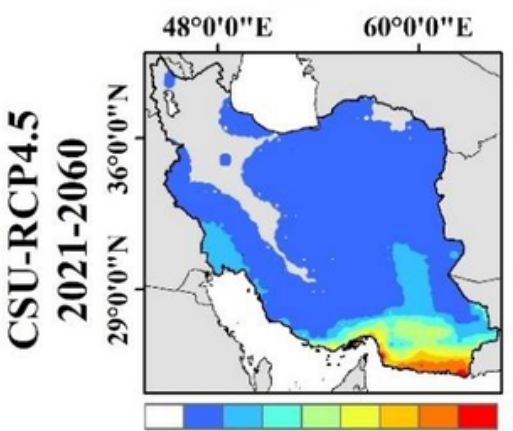

๑ ก

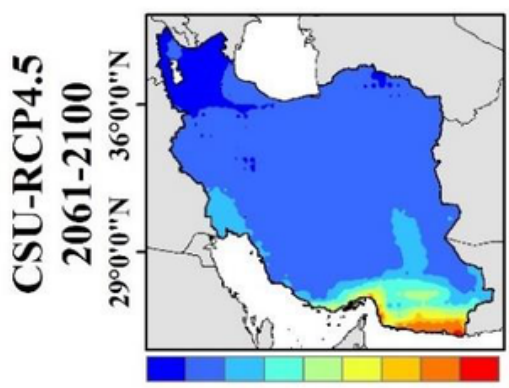

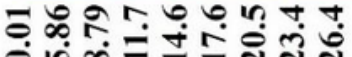

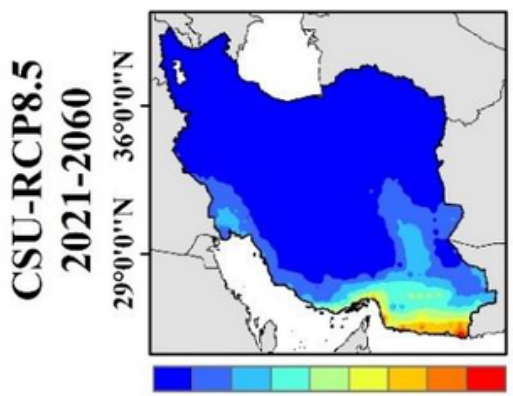

ๆ

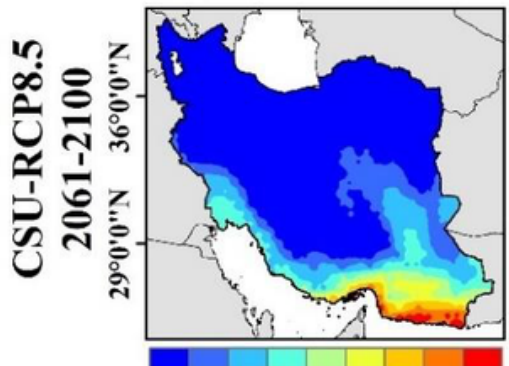

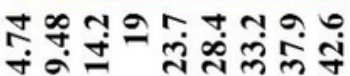

MAM

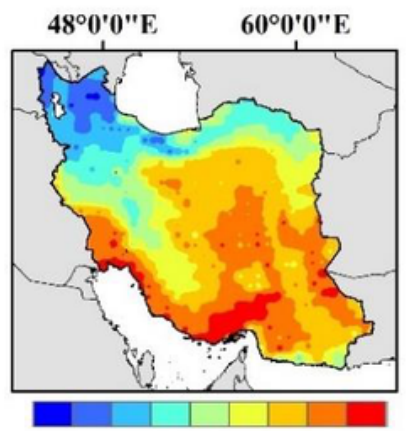

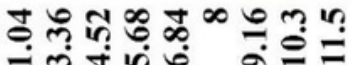

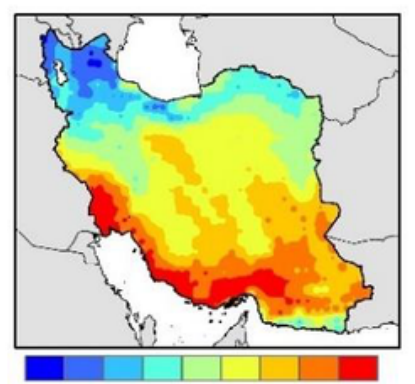

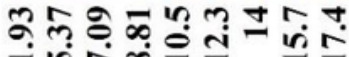

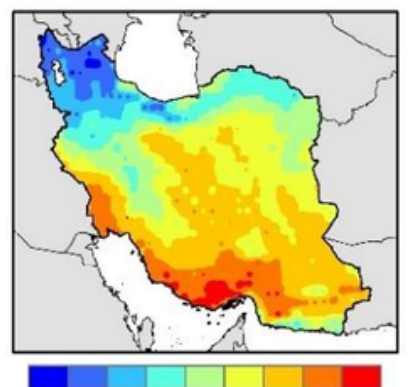

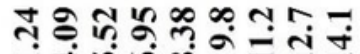

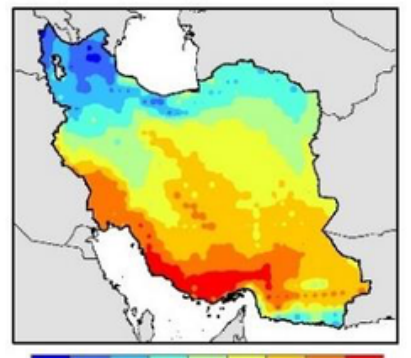
๙
JJA

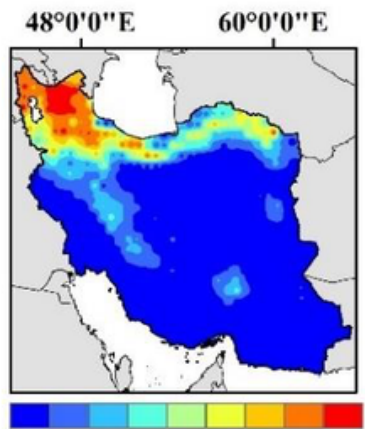

$\infty \neq N=\infty$ ㅁำ 두 $\infty$ m

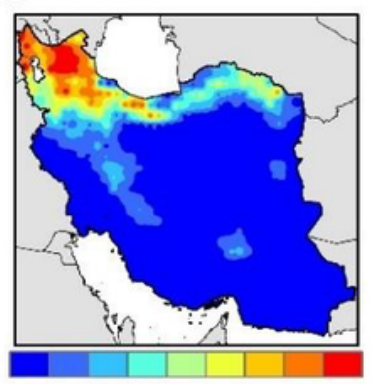

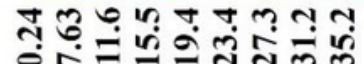

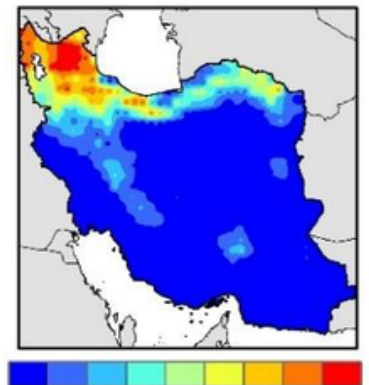

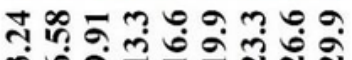
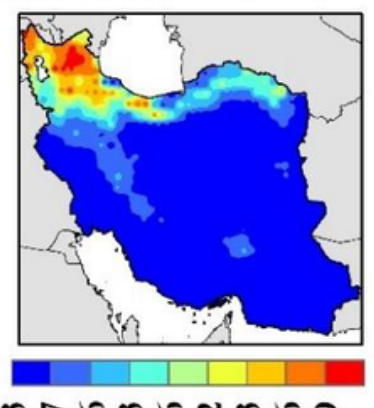

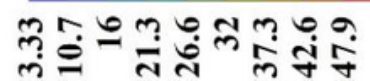

SON

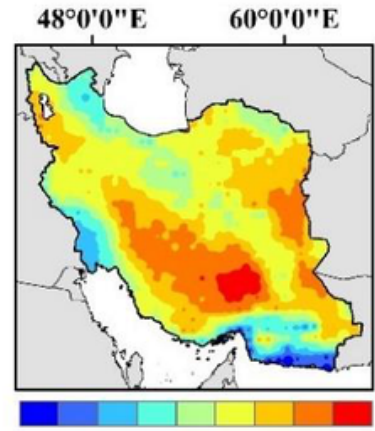

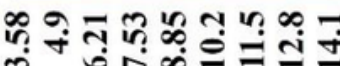

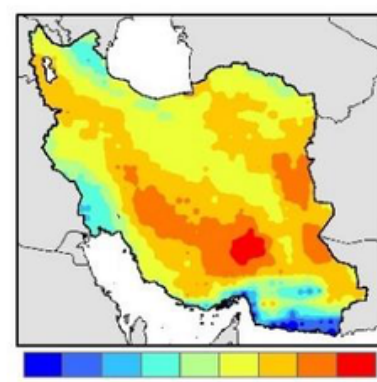

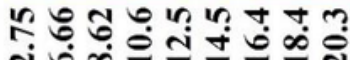

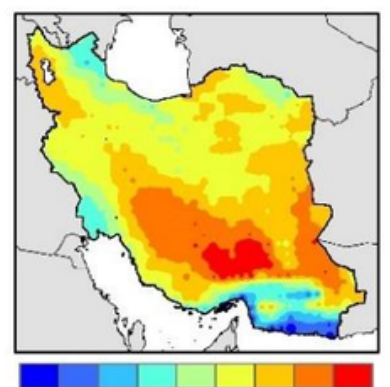

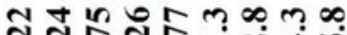
तु่

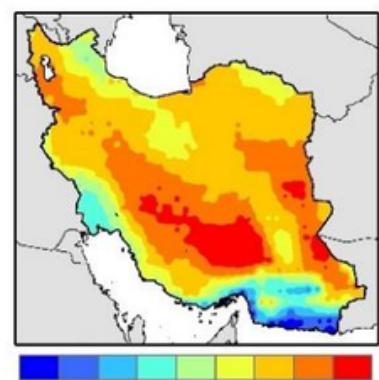

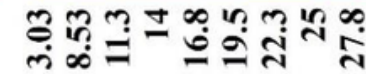

Figure 8

Projecting CSU Anomaly Index in Iran Using CMIP5 BC MME 
CSDI

WSDI

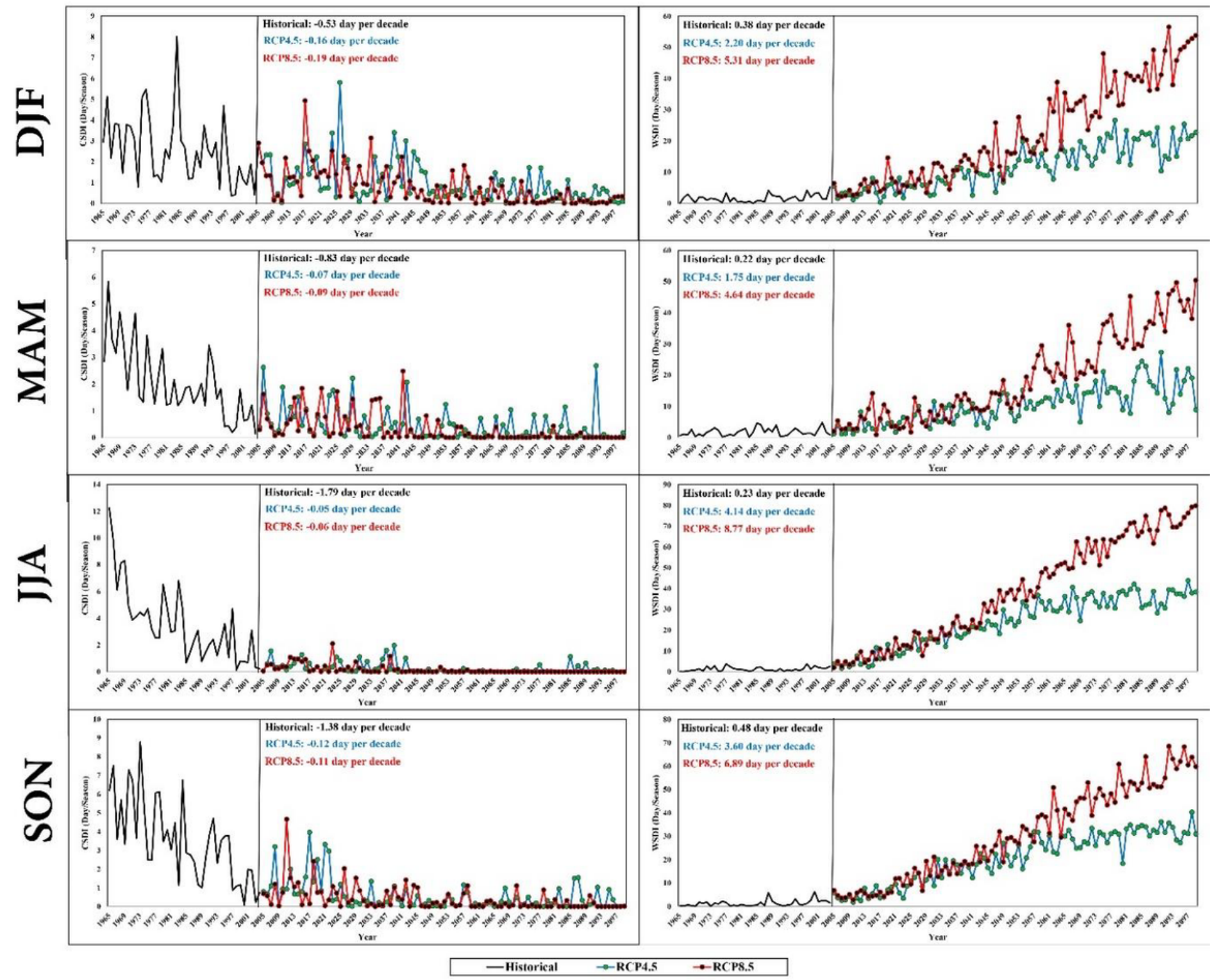

Figure 9

Long-term time series of CSDI and WSDI indices for area-averaged Iran based on CMIP5. The trend slope was calculated based on Theil-Sen's slope estimator test. 